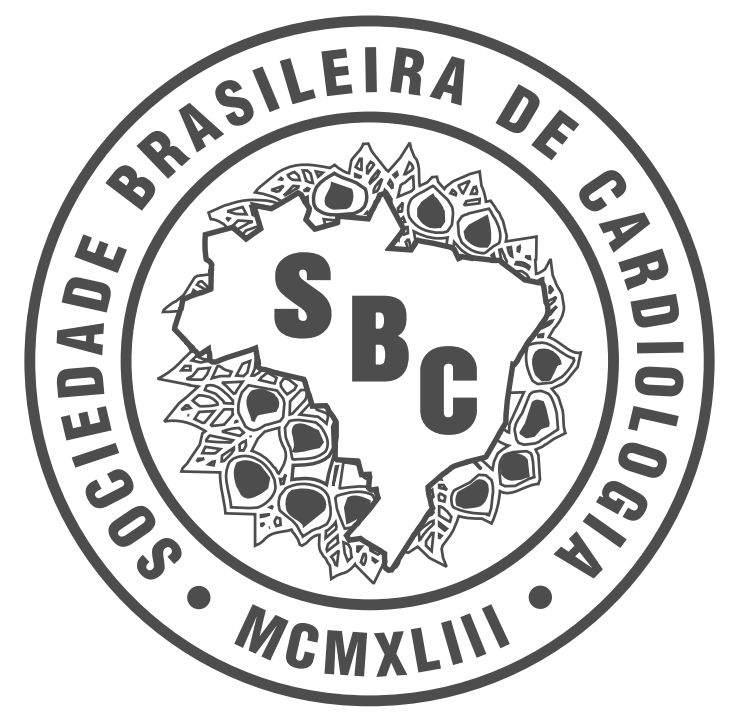

\title{
I DIRETRIZ DE PREVENÇÃO DA ATEROSCLEROSE NA INFÂNCIA E NA ADOLESCÊNCIA
}




\title{
EDITORES
}

\author{
Isabela de Carlos Back Giuliano (SC) \\ Bruno Caramelli (SP) \\ Lucia Pellanda (RS) \\ Bruce Duncan (RS), Sandra Mattos (PE) \\ Francisco H. Fonseca (SP)
}

\section{Membros}

Abel Pereira (SP), Abrahão Afiune Neto (GO), Adriana Forti (CE), Alessandra Costa (RJ), Alessandra Macedo (SP), Aline Raupp (RS), Ana Paula Chacra (SP), Andrea Brandão (RJ), Andréia A. Loures-Vale (MG), Bruce Duncan (RS), Bruno Caramelli (SP), Carlos Scherr (RJ), Celso Amodeo (SP), Danielle M. Blanco (SC), Deisi M. Vargas (SC), Emilio Moriguchi (RS), Fernanda Luisa Ceragioli Oliveira (SP), Francisco H. Fonseca (SP), Geodete Costa (SE), Hermes Toros Xavier (SP), Hilton Chaves (PE), Isa de Pádua Cintra (SP), Isabel Guimarães (BA), Isabela Giuliano (SC), Ivan Rivera (AL), Jayme Diament (SP), José Francisco Saraiva (SP), Leão Zaguri (RJ), Liliana Bricarello (SP), Lilton C. Martinez (SP), Lucia Pellanda (RS), Marcos Tambascia (SP), Maria Alayde Mendonça Silva (AL), Maria Arlete Meil Schmith Escrivão (SP), Maria C.O. Izar (SP), Maria M. L. Roiseman (RJ), Maria Marlene de Souza Pires (SC), Marilda Lipp (SP), Marileise Obelar (SC), Mario Coutinho (SC), Mauricio Laerte Silva (SC), Mauro Fisberg (SP), Neusa Forti (SP) Odwaldo Barbosa e Silva (PE), Osmar Monte (SP), Rafaella Nazário (RS), Raul Dias dos Santos (SP), Robespierre Queiroz da Costa Ribeiro (MG), Rosana Perim Costa (SP), Rose Vega Patin (SP), Roseli Sarni (SP), Sandra Mattos (PE), Sidney Fernandes (SP), Simone Reichert (RS), Tania Martinez (SP). 


\section{Realização}

- Departamento de Aterosclerose

Sociedade Brasileira de Cardiologia

- Departamento de Cardiologia Pediátrica

Sociedade Brasileira de Cardiologia

- Departamento de Cardiologia Pediátrica

Sociedade Brasileira de Pediatria

- Departamento de Endocrinologia Pediátrica

Sociedade Brasileira de Pediatria

- Departamento de Endocrinologia Pediátrica

Sociedade Brasileira de Endocrinologia e Metabologia

- Departamento de Hipertensão

Sociedade Brasileira de Cardiologia

- Departamento de Nutrologia Pediátrica

Sociedade Brasileira de Pediatria

Sociedade Brasileira de Hipertensão

- Diretoria de Normatizações e Diretrizes da

Sociedade Brasileira de Cardiologia

Correspondência: Prof. Dr. Bruno Caramelli • e-mail: bcaramel@usp.br 


\section{Definição do Problema e Objetivo da Diretriz}

Atualmente sabemos que é possível obter uma redução na incidência de complicações da aterosclerose com a adoção de um estilo de vida saudável e com o tratamento medicamentoso. Não há consenso, entretanto, em que fase da vida e de que forma a prevenção deve ser implantada. A medida em que foram sendo compreendidos os mecanismos de origem e desenvolvimento da doença aterosclerótica, consolidou-se o conceito de que este tratamento deve começar na infância. Ao invés de substituir o raciocínio clínico, esta diretriz pretende complementá-lo, tornando-se uma referência para o estabelecimento de estratégias individuais e populacionais no controle dos fatores de risco para aterosclerose na infância e adolescência.

\section{Metodologia e EvidênCias}

Os participantes desta diretriz foram selecionados entre especialistas das ciências da saúde com experiência assistencial e acadêmica em prevenção da aterosclerose. A metodologia e os níveis de evidência adotados foram os mesmos utilizados em documentos anteriores pela Sociedade Brasileira de Cardiologia.

Quadro I - Metodologia utilizada na execução da $1^{\text {a }}$ Diretriz de Prevenção da Aterosclerose na Infância e Adolescência

Recomendações:

- As diretrizes deverão ser baseadas em evidências;

- quando aplicável, deverá ser utilizada a divisão em classes;

- quando aplicável, deverá ser utilizada a divisão em graus de recomendação, segundo os níveis de evidência.

Grau ou Classe de Recomendação

I - Quando existe um consenso sobre a indicação.

Ila - Quando existe divergência sobre a indicação, mas a maioria aprova.

Ilb - Quando existe divergência sobre a indicação, com divisão de opiniões.

III - Quando existe um consenso na contra-indicação ou quando não for aplicável.

Níveis de Evidência.

A - Grandes ensaios clínicos aleatórios e metas-análises.

B - Estudos clínicos e observacionais bem desenhados.

C - Relatos e séries de casos.

D - Publicações baseadas em consensos e opiniões de especialistas.

\section{EpIDEMIOLOGIA no Brasil}

\section{Hipertensão}

Os estudos epidemiológicos sobre hipertensão (HAS) primária na infância e adolescência realizados no Brasil demonstraram uma prevalência que variou de $0,8 \%$ a $8,2 \%{ }^{1,2}$. A exemplo do que foi observado em adultos, muitos desses trabalhos demonstraram uma freqüente associação de HAS com sobrepeso ou obesidade.

\section{Sobrepeso e obesidade}

Nos últimos 30 anos, foi observado um rápido declínio da prevalência de desnutrição em crianças e adolescentes e uma elevação, num ritmo mais acelerado, da prevalência de sobrepeso/obesidade em adultos. A análise dos dados de crianças e adolescentes de 2 a 17 anos, da Pesquisa sobre Padrão de Vida (PPV), coletados no Brasil em 1997 pelo IBGE, demonstrou que a prevalência de obesidade foi de $10,1 \%$, sendo maior no Sudeste $(11,9 \%)$ do que no Nordeste $(8,2 \%)$; a prevalência de sobrepeso em adolescentes foi de $8.5 \%$ ( $10,4 \%$ no Sudeste e $6,6 \%$ no Nordeste) e a prevalência de obesidade em adolescentes foi de $3.0 \%$ ( $1,7 \%$ no Nordeste e $4.2 \%$ no Sudeste) $)^{3}$. A prevalência de excesso de peso foi maior nas famílias de maior renda, exceto em Porto Alegre, onde meninas de escolas públicas tinham IMC maior que as de escolas privadas ${ }^{4}$.

\section{Sedentarismo}

Há poucos estudos sobre a prevalência de sedentarismo em crianças e adolescentes no Brasil, variando de 42 a $93,5 \%, 4,5$, dependendo do critério utilizado.

\section{Dislipidemias}

Moura e colaboradores (1998-1999) estudaram em Campinas, SP, 1600 escolares com idades de 7 a 14 anos, identificando níveis médios de colesterol total, triglicerídeos, LDL-colesterol e HDL-colesterol, respectivamente, de 160, 79, 96 e $49 \mathrm{mg} / \mathrm{dL}^{6}$. Considerando os valores acima de $170 \mathrm{mg} / \mathrm{dl}$, os autores encontraram a prevalência de hipercolesterolemia de 35\%. Em amostra populacional do município de Florianópolis, em 2001, Giuliano identificou, em 1053 escolares de 7 a 18 anos, valores médios de colesterol total, triglicerídeos, LDL-colesterol e HDLcolesterol, respectivamente, de 162, 93, 92 e $53 \mathrm{mg} / \mathrm{dL}$. Nesse estudo, $10 \%$ dos indivíduos apresentaram hipercolesterolemia, 22\% hipertrigliceridemia, 6\% LDLcolesterol elevado e $5 \%$ HDL-colesterol baixo ${ }^{7}$.

\section{Tabagismo}

No Brasil, até a década de 1980, o hábito de fumar entre estudantes dos níveis fundamental e médio estava presente em 1 a 34\% dos jovens entrevistados. Trabalhos mais recentes demonstram que o tabagismo continua presente em 3 a 12,1\% dos adolescentes ${ }^{8}$. Entretanto, vale ressaltar que investigações realizadas em 10 capitais brasileiras, envolvendo 24.000 alunos de Ensino Fundamental e Médio, nos anos de 1987, 1989, 1993 e 1997, revelaram um aumento progressivo na experimentação de cigarros pelos jovens em todas as capitais. Outra conclusão importante da pesquisa de 1997 diz respeito à tendência de equilíbrio no consumo entre estudantes de ambos os gêneros, diferentemente do que ocorria no ano de 1987, quando o predomínio era do gênero masculino ${ }^{9}$. 


\section{Impacto em longo prazo}

Dados baseados no censo de $2000^{10}$ mostram as projeções de crescimento populacional brasileiro para 2050, com uma população estimada em 259,8 milhões de habitantes e mudanças na conformação da pirâmide populacional às custas de um aumento da expectativa de vida e menor taxa de fecundidade das mulheres, refletindo uma população envelhecida. Para contextualizar essas incidências no cenário mundial, um grupo internacional, recentemente, completou revisão de dados de mortalidade em vários países populosos em desenvolvimento (Rússia, China, Índia e África do Sul), utilizando dados do Estado do Rio Grande do Sul, para representar o Brasil. Esses autores demonstraram que a taxa de doenças cardiovasculares no Brasil é menor do que em países como os EUA e Portugal, mas quando essas análises consideram que a população do Brasil é mais jovem, o quadro muda. Extrapolando dados atuais de mortalidade por faixa etária, para a distribuição da população em 2040, o Brasil é o país que apresenta o maior aumento relativo das taxas de mortalidade entre todos os países avaliados.

\section{Mudanças socioculturais no Brasil determinantes do aumento do risco cardiovascular na infância e na adolescência}

A urbanização que ocorreu no século XX no Brasil e no mundo trouxe consigo sedentarismo, alteração nos hábitos alimentares com maior consumo de gorduras, ácidos graxos e de açúcares, redução da ingestão de alimentos ricos em fibras, tabagismo, estresse e o ingresso da mulher no mercado de trabalho ${ }^{11,12}$. Outra mudança de comportamento observada foi a preferência das famílias por refeições fora de casa, indicando a necessidade da promoção de uma alimentação saudável ${ }^{13}$.

\section{Evolução dos Fatores de Risco na Primeira Infância}

\section{Programação intra-uterina dos fatores de risco}

Os fatores de risco para a doença cardiovascular aterosclerótica estão presentes desde o útero e continuam ao longo de todo o curso da vida ${ }^{14,15}$. Quando o ambiente intra-uterino é desfavorável, o feto pode apresentar retardo de crescimento intra-uterino ou macrossomia. Estas condições clínicas foram associadas ao desenvolvimento tardio de diabetes, doença cardiovascular, dislipidemia e hipertensão arterial ${ }^{14,15}$.

Observações epidemiológicas realizadas nas duas últimas décadas demonstraram existir uma relação inversa entre peso ao nascimento e o desenvolvimento da doença cardiovascular na vida adulta. Estas observações levaram Barker e cols. a formularem a hipótese de uma programação intra-uterina para as doenças cardiovasculares ${ }^{16,17}$. Ao nascer, estas crianças apresentam níveis mais elevados de pressão arterial, de $\mathrm{ACTH}$, de endotelina plasmática e seu número de néfrons é inferior ao do RN adequado para a idade gestacional ${ }^{18}$. Embora a maior ênfase tem sido dada à nutrição fetal, outros fatores como infecções, estação do ano, fumo e o tamanho da mãe também podem estar relacionados ao desenvolvimento das doenças cardiovasculares ${ }^{19}$.

Conseqüências para o recém-nascido pequeno para a idade gestacional: dislipidemia, hipertensão arterial e função endotelial

Um recém-nascido é considerado pequeno para a idade gestacional (PIG) quando tem o peso para a idade gestacional igual ou menor do que o percentil 10. Por outro lado, é considerado de baixo peso quando temos menos de $2.500 \mathrm{~g}$ ao nascimento em conseqüência de retardo do crescimento intra-uterino (RCIU) ou de prematuridade. Recém-nascidos PIG apresentam maior incidência de doença cardiovascular - hipertensão arterial sistêmica e aterosclerose - e intolerância à glicose diabetes tipo II ou síndrome metabólica ${ }^{20}$.

Conseqüências para o recém-nascido grande para a idade gestacional: macrossomia, obesidade e síndrome metabólica

Macrossomia ou obesidade fetal é definida como peso ao nascimento maior do que o percentil 90 para a idade gestacional ou peso ao nascimento $>4 \mathrm{Kg}$ independente da idade gestacional ou sexo ${ }^{21}$. Estes bebês apresentam alterações no metabolismo dos carboidratos e lipídeos que podem persistir após o nascimento. A macrossomia fetal está associada ao desenvolvimento tardio de obesidade, diabetes e dislipidemia ${ }^{22}$. Estas observações são concordantes com a associação epidemiológica descrita por Barker entre os níveis lipídicos fetais e o risco de doença cardiovascular ${ }^{15,17}$.

Dentre as alterações detectadas, destacam-se a hiperglicemia, a hiperinsulinemia e elevação das concentrações séricas do VLDL-C, triglicerídeos e apoB lipoproteína ${ }^{23-26}$. Os principais marcadores lipídicos do risco aterogênico (apoB100/apo A-I; LDL-C/HDL-C; e $\mathrm{HDL} \cdot 3-\mathrm{C} / \mathrm{HDL}-2$ ) estão significativamente elevados no recém-nascido macrossômico quando comparado com um grupo controle ${ }^{23}$.

\section{Programação na primeira infância}

Os primeiros anos de vida são tão importantes na programação da saúde e da doença quanto a vida intrauterina. O crescimento retardado na infância pode estar associados aos ganhos de peso ou de altura inadequados. Tanto o crescimento retardado como o excessivo ("cruzamento dos percentis") podem ser fatores de risco para o 
desenvolvimento tardio das doenças crônicas. Uma associação entre retardo de crescimento no primeiro ano de vida e um risco elevado para doença coronariana foi descrita, independente do tamanho ao nascimento $27-29$.

Níveis mais elevados de pressão arterial foram observados em crianças que apresentaram crescimento intra-uterino retardado e maior ganho de peso na infância ${ }^{30}$.

Leite materno e obesidade, hipertensão e dislipidemia: mito ou verdade?

A amamentação materna exclusiva, de recém-nascidos termo e pré-termo, está associada com níveis significantemente mais baixos de pressão arterial na infância. 0 consumo preferencial de fórmulas artificiais, ao contrário, demonstrou níveis elevados de pressão arterial diastólica e média ${ }^{31}$, mas os resultados não são consensuais ${ }^{32-34}$.

Estudos observacionais indicaram que bebês que ingerem exclusivamente leite materno, rico em gorduras saturadas, apesar de apresentarem níveis elevados de colesterol no início da vida podem desenvolver uma regulação hepática do metabolismo das lipoproteínas. Desta forma, estas crianças que foram alimentadas com leite materno desenvolveriam posteriormente um perfil lipídico mais favorável quando comparadas a crianças que receberam fórmulas artificiais - tendem a permanecer em níveis iguais ou inferiores a $150 \mathrm{mg} / \mathrm{dl}$, e os primeiros apresentam perfil lipídico mais favorável na adolescência ${ }^{35,36}$

\section{BASES GenÉticas - IMPORTÂNCIA dos Poliformismos e Marcado- res Genéticos para a Prevenção da Aterosclerose na Infância E NA AdolescênCIA}

As principais causas de dislipidemias genéticas na infância e aquelas em que existe participação genética e ambiental são apresentadas na Tabela I. A suspeita de hipercolesterolemia familiar (HF) em crianças e adolescentes tem por base os critérios estabelecidos pelo programa de rastreamento familiar Make Early Diagnoses Prevent Early Deaths (MEDPED): valor de colesterol total $>270 \mathrm{mg} / \mathrm{dL}$ ou LDL-C > $200 \mathrm{mg} / \mathrm{dL}$ e parentes de primeiro grau com colesterol total $>220 \mathrm{mg} / \mathrm{dL}$ ou LDL-C > $155 \mathrm{mg} / \mathrm{dL}^{37}$.

\section{Estudos funcionais e genéticos}

Para um diagnóstico preciso das dislipidemias genéticas, devem ser realizadas provas funcionais, tais como o estudo do receptor de LDL em HF em modelos de culturas de células ou a atividade da lipase lipoprotéica (LLP) após heparina nos defeitos da LLP ou Apo Cll que se associam à síndrome da quilomicronemia. Algumas doenças, como a HF, são determinadas por uma grande série de mutações (mais de 700 descritas) e requerem rastreamento do gene de interesse por seqüenciamento.
Finalmente, é possível testar uma mutação conhecida por meio de reação em cadeia da polimerase seguida de técnicas de restrição enzimática ${ }^{38}$.

Na Tabela I são apresentadas as dislipidemias com forte tendência genética, assim como suas características principais.

\section{Aterosclerose como Fenômeno Precoce}

Estudos de autópsia após morte inesperada em crianças e adultos jovens demonstraram que a presença e a gravidade de lesões ateroscleróticas correlacionamse positiva e significativamente com os fatores de risco cardiovascular. 0 período de maior progressão das estrias gordurosas para placas fibrosas ocorre a partir dos 15 anos de idade ${ }^{39}$.

\section{Determinantes Biológicos e Correlações entre as Lipopro- TEÍNAS SÉRICAS NA INFÂNCIA}

Importância das características da coleta e da condição clínica da criança

Na presença dos outros fatores (diabetes, hipertensão, obesidade, tabagismo e sedentarismo), pode-se obter, inicialmente, apenas os valores do colesterol total plasmático ${ }^{40,41}$. Os pré-requisitos para a coleta de lípides em crianças e adolescentes estão bem definidos:

- estado metabólico estável;

- a dieta habitual e o peso devem ser mantidos por pelo menos duas semanas;

- intervalo de pelo menos oito semanas entre procedimento cirúrgico e tal coleta;

- nenhuma atividade física vigorosa nas 24 horas que antecedem o exame

- realizar jejum prévio de 12 a 14 horas; se necessário, pode ingerir água;

- realizar as dosagens seriadas sempre que possível no mesmo laboratório.

Na Figura 1 está descrito o algoritmo de triagem e seguimento de crianças com dislipidemia.

As condições clínicas e as drogas que mais influenciam o perfil lipídico encontram-se na Tabela II ${ }^{42,43}$.

Importância do método utilizado na análise das lipoproteínas

\section{Determinação do colesterol total}

O diagnóstico e o tratamento das hipercolesterolemias 


\section{Tabela I - Dislipidemias com forte componente genético e sua associação com aterosclerose ou pancreatite}

\begin{tabular}{|c|c|c|c|c|c|c|c|}
\hline Fenótipo lipídico & Alteração genética & Mutação & Modo de herança & Freqüência populacional & $\begin{array}{l}\text { Manifest. } \\
\text { infância }\end{array}$ & $\begin{array}{l}\text { Características clínicas } \\
\text { marcantes }\end{array}$ & $\begin{array}{c}\text { Associação com } \\
\text { aterosclerose prematura } \\
\text { (+ou-) ou pancreatite ( } \& \text { ) }\end{array}$ \\
\hline $\begin{array}{l}\operatorname{LDL} \uparrow \uparrow \uparrow \\
\text { (CT } \uparrow \uparrow)\end{array}$ & $\begin{array}{l}\text { Hipercolesterolemi } \\
\text { a familiar } \\
\text { Autossômica } \\
\text { recessiva } \\
\text { Sitosterolemia }\end{array}$ & $\begin{array}{c}\text { Receptor LDL } \\
\text { APO B Arg } 3500 \text { Gln } \\
\text { Peptídio sinal APO B } \\
\text { Proteína adaptadora } \\
\text { ARH } \\
\text { ABC G5/G8 }\end{array}$ & $\begin{array}{l}\text { Co-dominante } \\
\text { Dominante } \\
\text { Polimorfismos } \\
\text { recessiva } \\
\text { recessiva }\end{array}$ & $\begin{array}{c}1: 500 \text { (heterozigoto) } \\
1: 1.000 .000 \\
\text { (homozigoto) } \\
1: 700 \\
>1 \% \\
\text { rara, comum na Sardínia } \\
\text { Rara }\end{array}$ & $\begin{array}{l}+ \\
+ \\
+ \\
+ \\
+ \\
+\end{array}$ & $\begin{array}{l}\text { Xantomas tendinosos, } \\
\text { xantelasmas, arco } \\
\text { corneal precoces }\end{array}$ & +++ \\
\hline $\begin{array}{l}\text { CT } \uparrow \text { ou } \uparrow \uparrow \\
\text { LDL } \uparrow \text { ou } \uparrow \uparrow\end{array}$ & $\begin{array}{l}\text { Hipercolesterolemi } \\
\text { a poligênica }\end{array}$ & $?$ & Múltiplos genes & $1: 100$ ou $5: 100$ & + & - & + \\
\hline $\begin{array}{l}\text { LDL variável } \\
\text { (CT } \downarrow \text { ou } \uparrow)\end{array}$ & - & APO E 2, E3, E4 & Co-dominante & $\begin{array}{l}\text { Até } 5 \% \text { da variaçãa do } \\
\text { CT na população }\end{array}$ & $+\mathrm{ou}+1-$ & - & + quando for $\uparrow$ \\
\hline $\begin{array}{l}\text { VLDL } \uparrow \uparrow \text { e/ou } \\
\text { LDL } \uparrow \\
\text { (TG e/ou CT } \uparrow \text { ) }\end{array}$ & $\begin{array}{c}\text { Hiperlipidemia } \\
\text { familiar combinada }\end{array}$ & $\begin{array}{l}\text { APO Al-CIII-AIV? } \\
\text { LLP? e outros? }\end{array}$ & $\begin{array}{c}\text { Segregação } \\
\text { autossiômica } \\
\text { dominante }\end{array}$ & $0,5-1: 100$ & $+\mathrm{ou}+1-$ & - & ++ \\
\hline $\begin{array}{c}\text { VLDL } \uparrow \text { ou } \uparrow \uparrow \\
\text { TG } \uparrow \text { ou } \uparrow \uparrow\end{array}$ & $\begin{array}{l}\text { Hipertrigliceridemia } \\
\text { familiar }\end{array}$ & Várias & $\begin{array}{l}\text { autossômica } \\
\text { dominante, } \\
\text { (recessiva ou não } \\
\text { mendeliana) }\end{array}$ & $1: 300$ & $+\mathrm{ou}+1-$ & - & \& \\
\hline $\begin{array}{c}\text { VLDL } \uparrow \text { e HDL } \downarrow \\
\text { LDL pequenas e densas } \\
\text { CT } N \text { ou } \uparrow \\
\text { TG } N \text { ou } \uparrow\end{array}$ & $\begin{array}{l}\text { Síndrome } \\
\text { metabólica }\end{array}$ & $?$ & $?$ & Freqüente & $+1-$ & $\begin{array}{l}\text { Insulina } \uparrow, \text { intolerância à } \\
\text { glicose, HAS, } \\
\text { obesidade, } \\
\text { microalbuminúria, } \\
\text { fibrinogênio } \uparrow, \text { PAl-1 } \uparrow \text {, } \\
\text { ácido úrico } \uparrow\end{array}$ & ++ \\
\hline $\begin{array}{c}\operatorname{IDL} \uparrow \uparrow \uparrow \\
\left.(\mathrm{CT} \uparrow \uparrow \mathrm{e} T \mathrm{TG} \uparrow)^{2}\right)\end{array}$ & $\begin{array}{c}\text { Disbetalipoproteine } \\
\text { mia } \\
\text { (tipo III de } \\
\text { Fredrikson) }\end{array}$ & $\begin{array}{l}\text { APO E (E2E2) + } \\
\text { outros defeitos } \\
\text { genéticos LLP? }\end{array}$ & $\begin{array}{l}\text { Co-dominante } \\
\text { Não mendeliana }\end{array}$ & $\begin{array}{l}\text { Frequência de E2 1:100 } \\
\text { (da lipemia 1:5000) }\end{array}$ & $+1-$ & $\begin{array}{l}\text { Xantoma } \\
\text { estriado palmar }\end{array}$ & ++ \\
\hline $\begin{array}{l}\mathrm{Qm} \uparrow \uparrow \uparrow \\
(\mathrm{TG} \uparrow \uparrow \uparrow)\end{array}$ & $\begin{array}{c}\text { Hiper- } \\
\text { quilomicronemia }\end{array}$ & $\begin{array}{c}\text { LLP } \downarrow \downarrow \\
\text { APO CII } \downarrow \downarrow\end{array}$ & $\begin{array}{l}\text { Recessivo } \\
\text { Co-dominante }\end{array}$ & $\begin{array}{l}1: 1.000 .000 \\
\text { muito raro }\end{array}$ & + & $\begin{array}{c}\text { Pancreatite } \\
\text { Xantomas eruptivos } \\
\text { Lipemia retinal }\end{array}$ & $\&$ \\
\hline $\begin{array}{l}\text { HDL } \downarrow \downarrow \downarrow \\
\text { HDL } \downarrow \downarrow \downarrow\end{array}$ & $\begin{array}{l}\text { Fish-eye disease } \\
\text { Defic. Familiar } \\
\text { LCAT }\end{array}$ & $\begin{array}{l}\text { LCAT } \\
\text { LCAT }\end{array}$ & $\begin{array}{l}\text { Co-dominante? } \\
\text { Co-dominante? }\end{array}$ & Raro & + & $\begin{array}{l}\text { Opacificação córnea } \\
\text { Doença renal }\end{array}$ & $\begin{array}{l}+ \text { ou- } \\
+ \text { ou- }\end{array}$ \\
\hline $\begin{array}{l}\text { HDL } \downarrow \\
\text { HDL } \downarrow \downarrow \downarrow \\
\text { HDL } \downarrow \downarrow \downarrow\end{array}$ & $\begin{array}{c}\text { Tangier } \\
\text { Hipoalfalipoprotein } \\
\text { emia familiar }\end{array}$ & $\begin{array}{c}\text { APO AI Milano / Al- } \\
\text { CIII } \\
\text { ABC1 } \\
?\end{array}$ & $\begin{array}{l}\text { Polimorfismo } \\
\text { Recessivo } \\
\text { Dominante }\end{array}$ & $\begin{array}{l}>1 \% \\
\text { Muito raro } \\
\quad \text { Raro }\end{array}$ & $\begin{array}{l}- \\
+ \\
+\end{array}$ & Infiltração linfóide & $\begin{array}{l}+ \text { ou ? } \\
+\end{array}$ \\
\hline $\operatorname{Lp~(a)} \uparrow$ ou $\uparrow \uparrow$ & - & Apo (a) polimórfica & Co-dominante & ? & $+\mathrm{ou}+1-$ & - & +ou? \\
\hline
\end{tabular}

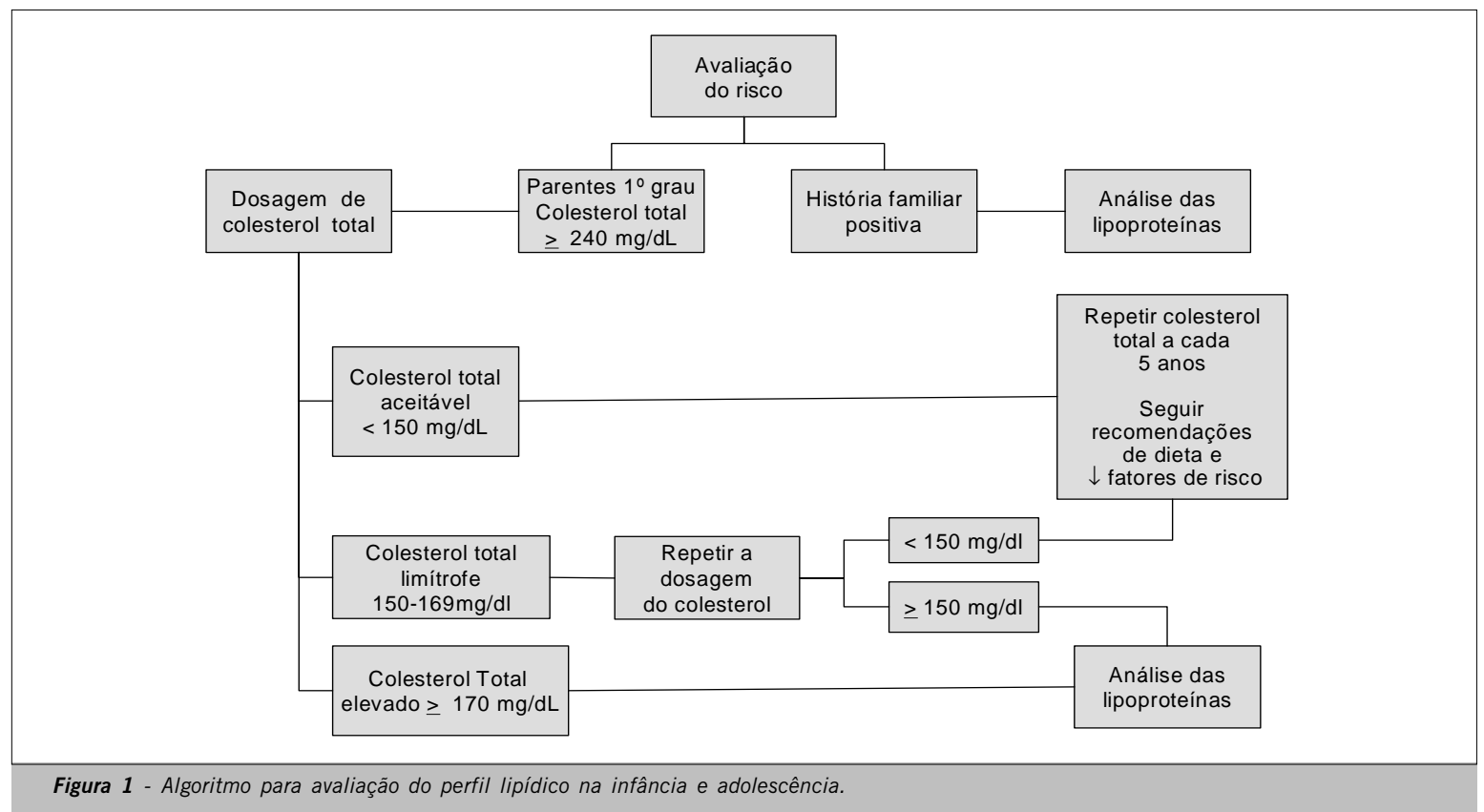




\begin{tabular}{|c|c|}
\hline $\begin{array}{l}\text { Anti-hipertensivos: tiazidas, clortalidona, espironolactona, beta-bloqueadores } \\
\text { Imunodepressores: ciclosporina, prednisolona, prednisona } \\
\text { Esteróides: estrógenos, progestágenos, contraceptivos orais } \\
\text { Anticonvulsivantes, ácido acetilsalicílico, ácido ascórbico, amiodarona, } \\
\text { alopurinol, terapia anti-retroviral. }\end{array}$ & $\begin{array}{l}\text { Hipotireoidismo, hipopituiritarismo, diabetes melito, síndrome } \\
\text { nefrótica, insuficiência renal crônica, atresia biliar congênita, doenças } \\
\text { de armazenamento, lúpus eritematoso sistêmico, sindrome da } \\
\text { imunodeficiência adquirida. }\end{array}$ \\
\hline
\end{tabular}

são baseados na avaliação dos níveis plasmáticos do colesterol total (CT) e da fração LDL-C. Em crianças pode-se utilizar a determinação de CT em estudos populacionais, por método capilar, pois este não depende do jejum para ser coletado. Na prática clínica, utilizando método não capilar, quando os níveis de colesterol total plasmático são maiores do que $200 \mathrm{mg} / \mathrm{dL}$, deve-se proceder à análise das lipoproteínas no jejum ${ }^{44}$.

\section{Determinação da fração LDL-C}

Quando necessária a determinação do perfil lipídico na infância, a fração LDL-C deve ser avaliada, utilizandose a fórmula de Friedewald:

\section{LDL-C = CT - HDL-C - Triglicérides $/ 5$}

Esta fórmula é válida para concentrações plasmáticas de triglicérides $<400 \mathrm{mg} / \mathrm{dL}$, pois acima destes, os valores de LDL-C são subestimados ${ }^{45}$. 0 jejum interfere na determinação tanto do LDL como do triglicerídeos ${ }^{46}$.

\section{O ambiente como determinante do perfil lipídico}

As modificações de hábitos e preferências alimentares introduzidas na infância podem se tornar permanentes. Entretanto, a ingestão de gorduras durante a lactância é fundamental para a mielinização do sistema nervoso central ${ }^{11}$ e as recomendações para uma dieta pobre em gorduras saturadas e colesterol só são aceitáveis para crianças acima de dois anos de idade ${ }^{13}$.

As gorduras saturadas são consideradas aterogênicas, pois, se ingeridas em excesso, são a principal causa dos aumentos do colesterol plasmático e do LDL-C(47). 0 colesterol contido na alimentação possui menor efeito sobre a colesterolemia plasmática do que as gorduras saturadas. Os ácidos graxos trans são ácidos graxos insaturados formados no processo de hidrogenação de óleos vegetais líquidos, como na produção de margarinas nas frituras e contribuem para o aumento do colesterol total, da fração LDL-C e diminuição do HDL-C ${ }^{48}$. A quantidade total de gordura na dieta deve estar entre $25 \%$ a $35 \%$ do total calórico por dia, sendo até $7 \%$ do tipo saturada, até $10 \%$ poli-insaturada e até $20 \%$ mono-insaturada ${ }^{5}$. 0 consumo dos ácidos graxos trans deve ser inferior a $1 \%{ }^{4}$ e a ingestão de colesterol não deve ultrapassar 200mg por dia ${ }^{48}$.

As gorduras poli-insaturadas são representadas, principalmente, pelo ácido linoléico (ômega 6) e pelo linolênico, EPA e DHA (ômega 3) e, no caso das monoinsaturadas, a principal fonte é o ácido oléico (ômega em óleos de girassol, milho e soja. Os ômega 3 (w-3), por sua vez, em óleos de peixe e de soja, óleo de canola nos peixes, principalmente os de água fria, e na semente de linhaça ${ }^{48}$. As gorduras mono-insaturadas (w-9), encontradas principalmente no azeite de oliva, óleo de canola, sementes oleaginosas, gergelim, abacate e azeitonas, foram relacionadas com melhora no perfil lipídico ${ }^{48}$. 0 consumo desproporcional entre $w-6 / w-3$ pode ter efeito aterogênico, aumentando os níveis de LDL-C.

Outros nutrientes para os quais existem evidências prováveis de redução do risco cardiovascular ${ }^{48}$ são os fitosteróis e as fibras solúveis ${ }^{47}$. Os fitosteróis são componentes naturais, encontrados em óleos vegetais como soja e girassol. Sua ação principal é a de reduzir o LDL-C por inibição na absorção intestinal de colesterol. As fibras solúveis (psyllium, pectinas, gomas, mucilagens e b-glucano) retardam o esvaziamento gástrico e o trânsito no intestino delgado, aumentam a tolerância à glicose e reduzem níveis elevados de colesterol e LDL-C. Suas principais fontes incluem as farinhas de aveia e de centeio integral, farelo de trigo, feijões, maçã, laranja e goiaba.

Para as crianças menores, as proteínas animais (aves sem peles, peixes e carnes magras) são consideradas alimentos complementares do leite materno ou de fórmulas infantis. Deve ser incrementado o uso de alimentos desnatados e laticínios magros.

\section{Hormônios sexuais endógenos e perfil lipídico}

Os níveis de lipídeos e lipoproteínas sofrem variações importantes durante a fase de crescimento e desenvolvimento humano, com diferenças segundo idade e sexo. Os níveis séricos de lipídeos e lipoproteínas são superiores nas crianças e adolescentes do sexo feminino, sendo esta diferença mais expressiva durante a adolescência. Em média, as meninas apresentam níveis superiores de colesterol total, HDL colesterol e LDL colesterol ${ }^{7,49,50}$.

As variações decorrentes da maturação sexual ocorrem em ambos os sexos. Nas meninas, observa-se um aumento progressivo do HDL colesterol a partir dos 10 anos, sendo este marcadamente superior ao dos meninos no final da adolescência. Também o LDL colesterol e o colesterol total elevam-se progressivamente a partir dos 14-15 anos nas meninas, sendo superiores aos dos meninos por volta dos 17-18 anos $^{51}$. Talvez a menarca seja importante no desencadeamento deste fenômeno na adolescência. Nos meninos, a maturação sexual acarreta diminuição progressiva do colesterol total, LDL e HDL-colesterol em função da evolução dos estágios puberais de Tanner. 


\section{Determinantes do Metabolismo dos Carboidratos e Associação com Outros Fatores de Risco}

\section{Mudanças do metabolismo durante o crescimento e o desenvolvimento}

Na puberdade, a resistência insulínica está aumentada, sendo compensada por aumento de sua secreção. A concentração de insulina plasmática em jejum aumenta de duas a três vezes durante o período do pico da velocidade de crescimento ${ }^{52,53}$. Nesta fase, há associação entre resistência relativa à insulina e facilitação da resposta insulínica à glicose no metabolismo dos aminoácidos, aumentando os efeitos anabólicos da insulina sobre o metabolismo protéico.

\section{Influência dos hormônios sexuais sobre a tolerância à glicose}

Durante a puberdade, em função do aumento de esteróides sexuais, há profundas mudanças na composição corporal e no perfil de secreções hormonais. $\mathrm{O}$ aumento do hormônio do crescimento $(\mathrm{GH})$ pode ser o determinante do aumento da resistência insulínica. Indivíduos predispostos podem não se adaptar a esta situação e, na presença de defeito na secreção de insulina, correm o risco de desenvolver a diabete melito tipo 2 na puberdade ${ }^{54}$.

\section{Importância da glicose e da insulina na ateros- clerose de crianças e adolescentes}

A hiperglicemia pode levar ao aumento na captação da glicose pelos tecidos e sua metabolização, por vias como a dos polióis e da glucosamina. Além disso, a hiperglicemia pode levar a glicação de proteínas extracelulares (como a LDL, que é mais aterogênica), geração de radicais livres (aumento do estresse oxidativo) e de produtos terminais de glicação avançada. A ligação desses produtos terminais aos receptores presentes no endotélio, músculo liso e fibroblastos pode levar ao aumento da permeabilidade vascular, da coagulação, diminuição da trombólise, maior proliferação celular e aumento da produção de proteínas da matriz extracelular. A geração de radicais livres pela hiperglicemia pode promover a aterogênese por meio da peroxidação da LDL (molécula mais aterogênica), pela oxidação do fibrinogênio (aumento da coagulação), por aumentar a ativação plaquetária pelo colágeno e por diminuir a produção de óxido nítrico ${ }^{55}$.

Os processos associados à hiperglicemia estão também envolvidos no espessamento da membrana basal, na formação de matriz extracelular, na angiogênese, no aumento da permeabilidade vascular, na proliferação de células musculares lisas, no aumento da adesão de células inflamatórias, na redução da fibrinólise e na exacerbação da disfunção endotelial ${ }^{56}$.

\section{Associação com hipertensão arterial}

A concentração plasmática de insulina é mais elevada e a captação total de glicose mediada pela insulina é reduzida em indivíduos jovens de peso adequado e com hipertensão essencial. Múltiplos mecanismos foram propostos para explicar a relação entre resistência insulínica e hipertensão: resistência à vasodilatação mediada pela insulina, alteração da função endotelial, maior atividade do sistema nervoso simpático, retenção de sódio, sensibilidade vascular aumentada ao efeito vasoconstrictor das aminas pressóricas e maior atividade do fator de crescimento levando à proliferação das paredes da musculatura lisa ${ }^{57}$.

\section{Índices insulino/glicêmicos}

Para avaliar a sensibilidade à insulina, vários índices foram desenvolvidos. Estudo realizado por Keskin e colaboradores, comparando os índices HOMA, relação glicemia/insulinemia e QUICKI, observou que o HOMA (Homeostasis Model Assessment - insulin resistance) é o método mais sensível e específico para avaliar sensibilidade insulínica. Além disso, determinou que o ponto de corte para adolescentes é de 3,16 , diferente dos adultos ${ }^{58}$

\section{Pressão arterial em crianças e adolescentes}

A partir de 1 ano de idade, a pressão arterial (PA) sistólica se eleva progressivamente até a adolescência. Já a PA diastólica se eleva após os 5-6 anos de idade, proporcional à sistólica. Os coeficientes de correlação da PA sistólica e da idade são maiores que os observados para a PA diastólica, assim como outras variáveis, tais como índices antropométricos e freqüência cardíaca. Nas crianças menores prevalecem as causas secundárias de hipertensão. A partir de 10 anos de idade, e principalmente na adolescência, predomina a causa primária de elevação da pressão arterial. A Tabela III mostra as principais causas de hipertensão arterial por faixa etária ${ }^{59}$.

\section{Tabela III - Causas de hipertensão arterial por faixa} etária na infância e na adolescência

\begin{tabular}{|ll|}
\hline Faixa etária & Causas \\
\hline Recém-nascidos & $\begin{array}{l}\text { Trombose e estenose de artéria renal, } \\
\text { malformações congênitas renais, coarctação } \\
\text { de aorta, displasia broncopulmonar. }\end{array}$ \\
\hline Lactentes - 6 anos & $\begin{array}{l}\text { Doenças do parênquima renal, coarctação } \\
\text { de aorta, estenose de artéria renal. }\end{array}$ \\
\hline $6-10$ anos & $\begin{array}{l}\text { Estenose de artéria renal, doenças do parên- } \\
\text { quima renal, coarctação da aorta; hiper- } \\
\text { tensão primária. } \\
\text { Adolescentes }\end{array}$ \\
\hline
\end{tabular}

A criança deve ficar em repouso, sentada, por pelo menos 5 minutos antes da obtenção da primeira medida da PA. A medida deve ser feita pelo menos duas vezes 
em cada consulta, preferencialmente no braço direito. 0 método de escolha é o auscultatório e o esfigmomanômetro deve ser de coluna de mercúrio. Em crianças menores de 3 anos é preferencial a utilização de método oscilométrico. Entretanto, recomenda-se que uma medida alterada observada seja confirmada pelo método auscultatório. A insuflação do manguito deverá ser feita 20 a $30 \mathrm{mmHg}$ acima da PA sistólica estimada, e a desinsuflação lenta: $2 \mathrm{mmHg}$ a cada segundo. 0 estetoscópio deve ser posicionado sobre o pulso da artéria braquial, proximal e medial à fossa cubital, abaixo da margem inferior do manguito ${ }^{60}$.

A largura do manguito deve ser $40 \%$ da circunferência do braço, na metade da distância entre o acrômio e o olécrano; e o seu comprimento, envolver 80 a $100 \%$ da circunferência do braço. Quando houver dúvida quanto ao melhor manguito a ser utilizado, o maior deve ser escolhido. A Tabela IV mostra os tamanhos de manguitos disponíveis ${ }^{60}$.

\begin{tabular}{|cccc|}
\hline $\begin{array}{c}\text { Tabela IV - Manguitos disponíveis para medida da } \\
\text { pressão arterial }\end{array}$ \\
\hline Manguitos & $\begin{array}{c}\text { Largura(cm) } \\
\text { Comprimento (cm) }\end{array}$ & $\begin{array}{c}\text { Circunferência máxi- } \\
\text { ma do braço (cm) }\end{array}$ \\
\hline Recém-nascidos & 4 & 8 & 10 \\
\hline Lactentes & 6 & 12 & 15 \\
\hline Crianças & 9 & 18 & 22 \\
\hline Adulto pequeno & 10 & 24 & 26 \\
\hline Adulto & 13 & 30 & 34 \\
\hline Adulto grande & 16 & 38 & 44 \\
\hline Coxa & 20 & 42 & 52 \\
\hline
\end{tabular}

A PA sistólica deverá ser anotada quando do aparecimento dos ruídos de Korotkoff (fase I) e a PA diastólica corresponderá ao desaparecimento dos ruídos (fase V). Em crianças, freqüentemente ouvem-se ruídos até $0 \mathrm{mmHg}$ e, nestes casos, devem ser anotadas as fases IV e $V$ de Korotkoff para a PA diastólicas. Para uma adequada medida da PA, deve-se evitar substâncias como café, chás e medicamentos como beta ${ }^{2}$ agonistas, antiinflamatórios não-hormonais, corticosteróides e vasoconstrictores nasais e anabolizantes orais ${ }^{60}$.

A monitoração ambulatorial da pressão arterial (MAPA) apresenta boa tolerabilidade e reprodutibilidade na faixa etária pediátrica. A suspeita de hipertensão do avental branco, hipotensão, resistência ao tratamento antihipertensivo, risco de lesão em órgão-alvo, hipertensão episódica, doença renal crônica, diabetes mellitus e disfunção autonômica são algumas das suas principais indicações. Recomenda-se a adoção do valor correspondente ao percentil 95 para o sexo, idade e percentil de altura como o limite para o período da vigília e valores $10 \%$ menores como pontos de corte para o período do sono ${ }^{61,62}$.

Dentre as diversas possibilidades de acometimento dos órgãos-alvo da hipertensão arterial sistêmica (HAS) em jovens, destacam-se as alterações da massa ventricular esquerda (MVE) ${ }^{63}$. A avaliação da MVE pode à potência $2,7\left(\mathrm{~m}^{2,7}\right)$, sendo o ponto de corte $51 \mathrm{~g} / \mathrm{m}^{2,7} 64$ ou corrigida pela estatura, sendo o ponto de corte 99,8 $\mathrm{g} / \mathrm{m}$ para meninos e $81 \mathrm{~g} / \mathrm{m}$ para meninas ${ }^{65}$. Todo jovem com HAS estabelecida deve realizar ecocardiograma para investigar a existência de hipertrofia ventricular esquerda (Grau de Recomendação lla; Nível de Evidência D). Sua presença indica maior rigor na abordagem terapêutica e repetição ao menos anual do exame. Em jovens, modificações estruturais do ventrículo esquerdo, relativas ao aumento da sua massa ou alterações da sua geometria, são mais precocemente encontrados do que anormalidades da função diastólica. Na infância, os valores de pressão arterial foram relacionados a maior espessamento médiointimal na carótida e menor complacência de grande artéria Entretanto, não há evidências que suportem a recomendação destas avaliações de forma rotineira na abordagem clínica do jovem hipertenso ${ }^{66}$.

Há poucas evidências de associação entre ingestão de sal e níveis tensionais em crianças. A sensibilidade ao sódio em crianças e adolescentes parece se relacionar à história familiar e presença de obesidade. A ingestão de potássio se relaciona inversamente com a PA em crianças, porque o potássio interfere na regulação da PA induzindo natriurese e suprimindo a produção e a liberação de renina ${ }^{67}$.

Além do sexo e da idade, múltiplos fatores correlacionam-se à PA em crianças e adolescentes. Estes fatores podem ter determinismo genético ou ambiental e a maioria sofre interferência de ambos, como pode ser observado no Quadro II. O peso e o índice de massa corpórea (IMC) são as variáveis que apresentam a mais forte correlação com a PA nesta faixa etária, notadamente com a PA sistólica. As diferenças observadas entre os sexos são discretas e podem representar diferentes estágios de maturação sexual. Em sinergia à presença de obesidade, há uma forte correlação entre a PA de pais e filhos, notadamente entre mães e filhos, justificando uma abordagem preventiva mais cuidadosa de famílias com $\mathrm{HAS}^{68}$.

\section{Composição Corporal, Obesi- DADE E A AsSOCIAÇÃo COM Outros Fatores de RISCO}

\section{Correlação entre obesidade na infância e adolescência e obesidade na vida adulta}

Há descrições de relação direta entre a gravidade da obesidade na infância e o risco desta criança manter-se com sobrepeso ou obesidade na vida adulta. Esta associação parece ser mais forte do que aquela entre peso do indivíduo na vida adulta e o peso de seus pais. Sugere-se que talvez os fatores ambientais estejam mais implicados na perpetuação da obesidade durante o crescimento e desenvolvimento do que fatores genéticos ${ }^{69}$. A partir da segunda década de vida, esta correlação se intensifica ocorrendo maior risco de distúrbios do 
Quadro II - Fatores relacionados aos níveis de pressão arterial em crianças e adolescentes.

Fatores genéticos: pressão arterial de pais e irmãos, sensibilidade ao sal, obesidade, deleção no gene da ECA.

Fatores ambientais: nível socioeconômico, peso ao nascer, atividade física.

Fatores genéticos e ambientais: altura, peso, índice de massa corporal, freqüência cardíaca, crescimento somático e maturação sexual, ingestão de sódio e outros macronutrientes, reatividade do sistema nervoso simpático, estresse.

metabolismo dos lípides e hipertensão arterial sistêmica mais tarde. Porém, o índice de massa corporal normal na infância ou adolescência não garante uma proteção contra obesidade. Quando analisada a associação entre peso materno e gênero, as meninas, filhas de mães obesas, apresentam maior risco de tornarem-se adultas obesas do que os meninos, talvez pela maior sensibilidade daquelas ao exemplo de comportamento alimentar da mãe e ao estímulo de maior consumo calórico ${ }^{70}$.

\section{Obesidade geral, distribuição da gordura corporal e outros fatores de risco}

\section{Dislipidemias}

Há uma associação positiva entre a incidência da obesidade e dislipidemia em crianças. Foram encontradas prevalências de cerca de $50 \%$ de dislipidemia em crianças com índice de massa corporal acima de percentil 99 para a idade, sendo a obesidade considerada um critério para triagem de perfil lipídico em crianças e adolescentes. 0 mecanismo que explica a associação talvez seja a ativação da via da cinase AMP-dependente, induzida pelo aumento da insulina e da leptina e redução da ativação da adiponectina, que por sua vez aumenta a oxidação dos ácidos graxos. Nestas crianças, a adiponectina possui uma associação positiva com a sensibilidade à insulina e com os níveis de HDL-colesterol e negativa com os níveis de triglicerídeos. Por outro lado, a dislipidemia na infância pode estar associada ao desenvolvimento de obesidade na vida adulta, especialmente no sexo feminino. Isto pode sugerir que haja algum mecanismo geneticamente determinado que explique a associação dessas variáveis ${ }^{71}$.

Quanto menor a partícula de LDL, provavelmente maior será o seu poder de aterogênese. As crianças obesas parecem ter um maior percentual de LDL de padrão B (partículas menores) do que as crianças com peso normal para a estatura. Assim, mesmo nas crianças obesas com níveis normais de LDL-colesterol, o seu perfil lipídico pode ser menos favorável, dada a proporção entre as subclasses de suas lipoproteínas ${ }^{72}$. Estudos demonstram que as crianças obesas apresentam maiores níveis de lipoproteína a [Lp(a)], independente de sua história familiar. Os níveis de homocisteína parecem ter relação direta com os de insulina nas crianças obesas ${ }^{73}$.

\section{Hipertensão arterial}

O aumento da prevalência mundial de hipertensão arterial primária na infância e adolescência guarda relação direta com o aumento da prevalência de obesidade. Há uma relação direta entre o grau da obesidade e o risco de hipertensão arterial sistêmica na infância ${ }^{74}$. Vários mecanismos procuram explicar a relação entre obesidade e hipertensão: os distúrbios do metabolismo da insulina, aumento do tônus simpático, diminuição do tônus vagal, alterações vasculares estruturais e funcionais, aumento da agregação plaquetária e do estresse oxidativo, com queda dos níveis de óxido nítrico, além da possibilidade de distúrbios do sono, como previamente descrito em adultos ${ }^{75}$.

História familiar de hipertensão arterial parece ter um efeito sinérgico ao impacto da obesidade sobre os níveis tensionais na infância e adolescência. Parecem ser também fatores associados à hipertensão arterial em crianças obesas: hiperinsulinemia, hiperleptinemia e distribuição centrípeta da gordura corporal ${ }^{76}$. A hipertensão arterial sistêmica pode determinar complicações cardiovasculares já na infância ou adolescência, como a hipertrofia ventricular esquerda. Este risco parece ser tanto maior quanto maior o percentil de índice de massa corporal, demonstrando uma ação aditiva entre obesidade e hipertensão arterial neste desfecho ${ }^{77}$.

\section{Inflamação e disfunção endotelial precoce}

Os níveis séricos de proteína $C$ reativa de alta sensibilidade apresentam uma relação direta com a intensidade da obesidade na infância, podendo ser um marcador da aceleração da progressão da aterosclerose. Isto não significa que a dosagem da PCR de alta sensibilidade deva ser incluída na avaliação laboratorial rotineira de crianças obesas.

Há descrições de disfunção endotelial precoce nas crianças e adolescentes obesos. Esta disfunção parece ter uma relação mais forte com os níveis de leptina séricas do que com a intensidade da obesidade. As crianças com obesidade grave apresentam espessura médio-intimal carotídea significativamente maior do que as com peso normal. Parecem ser fatores associados a este espessamento: níveis elevados de insulina, hipertensão arterial, níveis baixos de apolipoproteína A1 e obesidade truncal ${ }^{63}$.

\section{Métodos no Diagnóstico dos FATORES DE RISCO}

\section{Dislipidemia}

Sabemos que as crianças cujos pais apresentem hipercolesterolemia têm uma possibilidade maior de também apresentarem esta dislipidemia ${ }^{78}$. A análise do perfil lipídico deve ser feita em crianças que:

- tenham pais ou avós com história de aterosclerose 
com idade menor que 55 anos;

- tenham pais com CT >240 mg/dL;

- apresentem outros fatores de risco, como hipertensão arterial, obesidade, tabagismo ou dieta rica em gorduras saturadas e/ou ácidos graxos trans;

- utilizem drogas ou sejam portadoras de doenças que cursam com dislipidemia (SIDA, hipotiroidismo, etc);

- possuam manifestações clínicas de dislipidemias (xantomas, xantelasmas, arco corneal, dores abdominais recorrentes, pancreatites).

Toda criança, a partir de 10 anos de idade, deve ter uma determinação do CT por meio de exame em sangue capilar da polpa digital. As crianças que apresentarem CT $>150 \mathrm{mg} / \mathrm{dL}$ e $<170 \mathrm{mg} / \mathrm{dL}$ deverão ter seus pais orientados em relação a medidas de mudança de estilo de vida, devendo ter este exame repetido anualmente; as crianças com CT > $170 \mathrm{mg} / \mathrm{dL}$ deverão ser submetidas à análise completa de lípides, após jejum de 12 horas (Grau de Recomendação Ilb; Nível de Evidência D).

Os valores de referência propostos para os lípides séricos na infância e adolescência estão descritos na Tabela V (Grau de Recomendação Ilb, Nível de Evidência D). Em relação à hipertrigliceridemia na infância, um nível de triglicérides entre 100 e 200 mg/dL geralmente está relacionado à obesidade e acima de $200 \mathrm{mg} / \mathrm{dL}$, geralmente relacionado a alterações genéticas.

\begin{tabular}{|cccc|}
\hline Tabela V - Valores de referência lipídica propostos \\
para a faixa etária de 2 a 19 anos
\end{tabular}

\section{Hipertensão}

A Tabela VI mostra a classificação da pressão arterial na infância e na adolescência. Observa-se que hipertensão arterial estará configurada quando os valores de pressão arterial sistólica e/ou diastólica forem maiores ou iguais ao percentil 95 para sexo, idade e percentil de altura, em três ocasiões distintas. Cabe ressaltar que a faixa denominada pré-hipertensão deve ser valorizada e identificada com a finalidade de adoção de medidas preventivas rigorosas.

Tabela VI - Classificação da pressão arterial em
crianças e adolescentes

Os valores correspondentes aos diferentes percentis de PA, por sexo, idade e percentil de altura estão expostos nas Tabelas VII e VIII. Ressalta-se que estes valores foram obtidos para a população americana. Não dispomos de dados representativos para a população brasileira, razão pela qual é recomendada a adoção desta tabela. Para que os valores de PA correspondentes aos percentis 90 , 95 e 99 sejam identificados para um dado indivíduo, é necessário seguir alguns passos:

- utilizar a tabela correta para o sexo da criança ou adolescente;

- localizar a linha correspondente à idade na tabela;

- identificar o percentil de altura da criança ou adolescente pelos gráficos de estatura disponíveis nos "sites" abaixo ${ }^{79}$ :

\section{a. meninos:}

\section{i. de 0 a 36 meses}

http://www.cdc.gov/nchs/data/nhanes/growthcharts/ set1clinical/cj41c017.pdf

ii. de 2 a 20 anos

http://www.cdc.gov/nchs/data/nhanes/growthcharts/ set1clinical/cj41c021.pdf

\section{b. meninas:}

\section{i. de 0 a 36 meses}

http://www.cdc.gov/nchs/data/nhanes/growthcharts/ set1clinical/cj41c018.pdf

ii. de 2 a 20 anos

http://www.cdc.gov/nchs/data/nhanes/growthcharts/ set1clinical/cj41c022.pdf

- localizar a coluna correspondente ao percentil de altura;

- observar o valor correspondente ao percentil desejado na linha correspondente para a idade e o percentil de altura.

Crianças acima de 3 anos devem ter a medida da sua PA obtida em toda avaliação de saúde, pelo menos uma vez ao ano (Grau de Recomendação Ilb; Nível de Evidência D). Crianças com fatores de risco para hipertensão devem ter a aferição realizada mais precocemente ${ }^{60}$. Se a pressão arterial apresentar comportamento na faixa préhipertensão, nova medida deve ser feita no prazo máximo de 6 meses. Caso a pressão aferida seja caracterizada como anormal, este comportamento deve ser confirmado em mais duas ocasiões e este jovem encaminhado para tratamento conforme descrito anteriormente.

\section{Obesidade}

O índice de massa corpórea (IMC), definido pelo peso em quilogramas dividido pela altura em metros ao quadrado, é considerado a medida padrão para o sobrepeso e obesidade. Embora este índice apresente grande associação com a adiposidade na infância e adolescência, é importante destacar que o mesmo apresenta variação de acordo com a idade e o sexo, sendo necessária sua avaliação a partir de curvas 


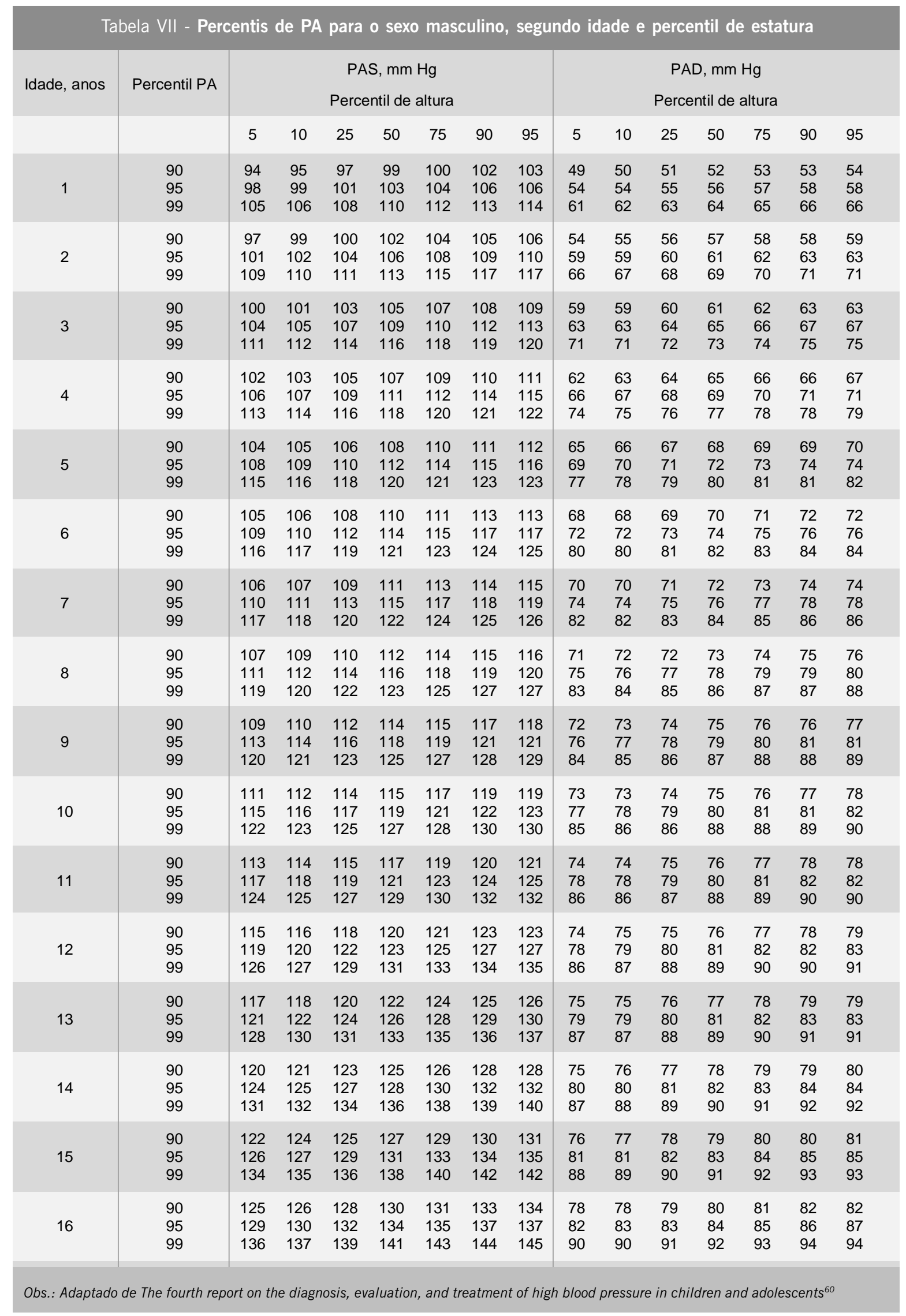




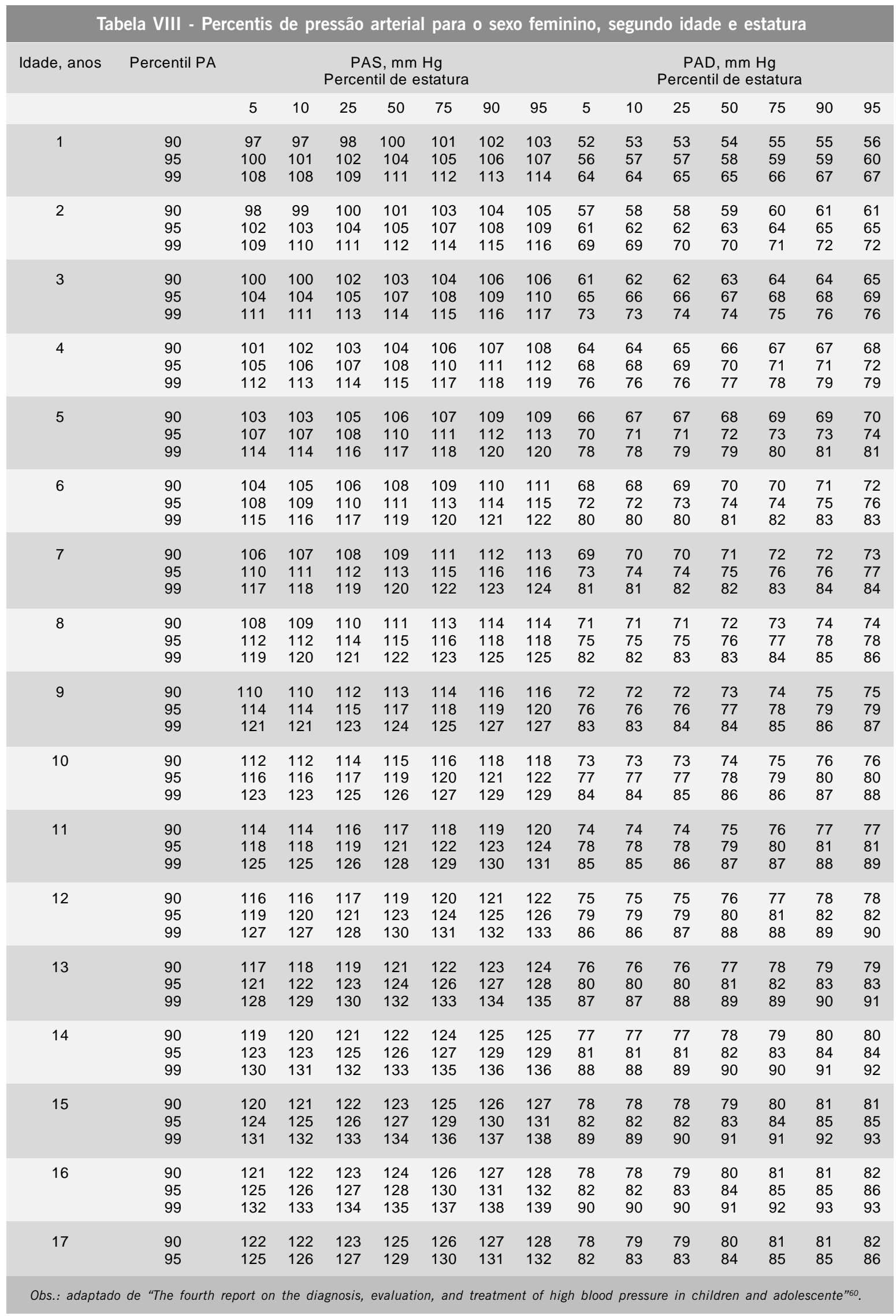


específicas. Mais recentemente, a medida da circunferência abdominal tem sido proposta para uma melhor avaliação da obesidade visceral.

Recentemente, o National Center for Health Statistics (NCHS) elaborou gráficos de referência, recomendando que as crianças com IMC > percentil 95 sejam classificadas como obesas e aquelas com IMC entre os percentis 85 e 95 como portadoras de sobrepeso. As curvas do IMC foram mostram os valores de referência para as idades de 2 a 20 anos, para ambos os sexos e podem ser encontradas no "site" do CDC-NCHS"9:

\section{- Meninos:}

http://www.cdc.gov/nchs/data/nhanes/growthcharts/ set1clinical/cj41c023.pdf

\section{- Meninas:}

http://www.cdc.gov/nchs/data/nhanes/growthcharts/ set1clinical/cj41c024.pdf

As crianças e os adolescentes obesos devem realizar análise do perfil lipídico, da glicemia e insulinemia de jejum ao lado da medida da pressão arterial. Além disso, devem ser pesquisadas doenças relacionadas como a apnéia do sono e hipoventilação, alterações menstruais como oligomenorréia, amenorréia, estrias e hirsutismo e alterações de pele como a acanthosis nigricans, ortopédicas, esteatohepatite, hipotireoidismo e desordens psicológicas, sendo muitas vezes conveniente uma avaliação especializada (Grau de Recomendação Ilb; Nível de Evidência D).

\section{Resistência à insulina}

A síndrome de resistência à insulina deve ser considerada como um tema em evolução e os seus critérios diagnósticos, ainda preliminares. O primeiro passo é identificar as crianças e adolescentes com benefício de intervenção e sob risco de desenvolvimento de diabetes:

- crianças com sobrepeso ou obesidade;

- aquelas com história familiar de diabete melito tipo 2;

- as de etnia com maior predisposição ao desenvolvimento do diabetes tipo 2 (populações indígenas, africanas, asiáticas ou hispânicas);

- aquelas que apresentem sinais ou condições associadas com a resistência à insulina (acantosis nigricans, hipertensão arterial, dislipidemia, síndrome do ovário policístico).

Nestas condições, recomenda-se a obtenção da glicemia de jejum (Grau de Recomendação Ilb; Nível de Evidência D). A determinação da resistência à insulina, entretanto, é mais complicada e envolve técnicas aplicáveis apenas à pesquisa, como o clamp euglicêmico. Uma alternativa tem sido a mensuração da insulina plasmática em jejum (normal $<15 \mathrm{mU} / \mathrm{L}$, limítrofe alto 15 a $20 \mathrm{um} / \mathrm{L}$, alto $>20 \mathrm{um} / \mathrm{L}$ ). Além disso, relações com a glicemia e teste oral de tolerância à glicose têm sido sugeridos.
Devido ao importante papel da obesidade na síndrome, ênfase especial deve ser dado a prevenção ou controle do sobrepeso e obesidade. Como a síndrome é complexa, uma avaliação de especialistas em desordens endocrinológicas, lipídicas, hipertensão arterial, obesidade ou transtornos psicológicos pode ser necessária ${ }^{80}$.

\section{Dieta aterogênica}

Para o diagnóstico da dieta aterogênica, pode ser utilizado o recordatório alimentar de 24 horas ou de 3 dias (dois dias da semana e um do final de semana), que consiste em definir e quantificar os alimentos ou bebidas ingeridas pelo referido período. 0 questionário de freqüência alimentar permite também a obtenção de informações adicionais sobre grupos de alimentos em particular, que sejam consumidos de forma habitual. É importante a detecção de uma ingestão excessiva de ácidos graxos saturados e trans, sódio e carboidratos simples, frituras e alimentos competitivos ${ }^{81}$.

\section{Sedentarismo}

A avaliação da atividade física deve ser examinada em relação ao tempo e nível de exercício, bem como o tempo gasto com atividades físicas junto com a família. Por outro lado, também é conveniente verificar o tempo despendido com jogos eletrônicos, televisão, computador. O tempo de inatividade recreacional deve ser limitado (exemplo < 2 horas de TV/dia). Deve-se utilizar o Questionário Internacional de Atividade Física (IPAQ), no qual a atividade física total é avaliada por METs/minuto/semana e também é registrado o tempo total sentado. A atividade física diária é considerada como de grau moderado quando corresponde a um gasto energético de 3,3 a 4,0 METs e vigorosa quando superior a 5,5 METs ( $1 \mathrm{MET}=3,5 \mathrm{ml}$ de consumo de $\mathrm{O}_{2} / \mathrm{kg} /$ minuto). A recomendação atual é de aproximadamente 30 minutos de atividade física moderada na maior parte dos dias (150 minutos/semana), mas idealmente a criança deve realizar cerca de 60 minutos diários de atividade física moderada ${ }^{82}$.

Alguns estudos mostraram que a TV influencia a dieta das crianças, levando a uma composição excessiva em sal, carboidratos simples, gordura saturada ou trans. Esta influência acaba por ser transmitida aos lanches consumidos nas escolas.

\section{A Atividade Física na Prevenção da Aterosclerose na InfânCia}

Do ponto de vista da prevenção da doença aterosclerótica, os trabalhos sobre atividade física em jovens investigaram o nível de atividade física por eles realizada, o resultado de intervenções na escola e na comunidade sobre educação em saúde, as estratégias que elevam o nível de atividade física e o resultado da atividade física na prevenção ou no controle dos fatores de risco cardiovascular. Não existem, portanto, resultados 
de intervenções sobre a atividade física em crianças e adolescentes e sua associação com redução da doença aterosclerótica do adulto ${ }^{83}$.

Vale ressaltar que, em 1996, um relatório do Ministério da Saúde dos Estados Unidos deixou claro que os benefícios da atividade física não estão limitados a indivíduos adultos, já que a realização de atividade física de forma regular pelas crianças e adolescentes ajuda a construir e a manter articulações, músculos e ossos saudáveis; ajuda no controle do peso, reduzindo a gordura e aumentando a massa muscular; previne ou retarda o desenvolvimento de hipertensão arterial sistêmica e ajuda a reduzir os níveis de pressão arterial em adolescentes hipertensos, além de reduzir os sentimentos de depressão e ansiedade. 0 incentivo à adoção de um estilo de vida ativo deve iniciar-se o mais precocemente possível (a AHA estabelece a partir dos 2 anos de idade), mantendose por toda a adolescência até a vida adulta ${ }^{80.83}$.

Como orientação geral, as crianças saudáveis devem ser encorajadas a praticar atividade física, de forma prazerosa, no lazer ou sob a forma de exercícios físicos programados ou em atividades esportivas, no mínimo trinta minutos por dia, três a quatro vezes por semana, para adquirir aptidão física ("fitness"). As necessidades individuais deverão ser respeitadas, no que diz respeito ao gênero, idade, grau de maturação sexual, presença de limitações físicas ou mentais que impeçam a realização de exercícios, nível econômico, bem como fatores familiares e do ambiente da criança ${ }^{80,83}$.

\section{O papel do médico na promoção da atividade física na infância}

Os profissionais da saúde, dentre eles o médico, desempenham um papel importante na educação para a promoção da saúde de crianças e adolescentes no que diz respeito à atividade física e a outros comportamentos saudáveis. Para a programação da prática de atividade física regular pela criança e seus familiares, nas consultas de rotina em indivíduos saudáveis (sem limitações), com doenças crônicas (físicas ou mentais), com fatores de risco cardiovascular ou com necessidades especiais, devem ser investigados ${ }^{83-86}$ :

- a atividade física no ambiente escolar ou fora dele;

- a atitude da família em relação à participação em programas de exercícios, brincadeiras e jogos e ao tempo gasto pela criança em atividades sedentárias;

- o acesso da criança a locais próprios para a prática de atividade física, dentro e fora da escola;

- o encorajamento familiar à prática de atividade física pela criança.

\section{Recomendações ao profissional da saúde s3-86 $^{80}$}

- Incluir, como rotina, a orientação para a atividade física na sua prática profissional; física regular;

- identificar, através da história clínica, exame físico e avaliação complementar quando necessário, a existência de doenças que contra-indiquem prática de exercícios;

- incentivar a criança e o adolescente a participar ativa e prazerosamente de atividades não-estruturadas, de jogos e de esportes organizados;

- orientar as crianças a praticar atividade física apropriada para a sua idade e fase de desenvolvimento, por no mínimo 30 minutos, em todos os dias da semana;

- orientar os adolescentes a realizar ao menos três sessões de atividades físicas moderadas ou intensas por semana, com duração de, pelo menos, 20 minutos;

- incentivar as crianças e adolescentes que já se encontram em prática regular de atividade física a se manterem na mesma;

- instruir e incentivar crianças e adolescentes que apresentam fatores de risco cardiovascular a realizarem atividade física para auxiliar no controle dos mesmos;

- orientar atividade física apropriada para crianças com necessidades especiais ou limitações;

- instruir os pais a planejar atividade física (jogos, brincadeiras, esportes) ao invés de refeições como parte da recompensa ao bom desempenho da criança;

- instruir os pais a estabelecerem limites para atividades que não exigem dispêndio de energia (televisão, jogos eletrônicos, computador, tempo ao telefone);

- instruir os pais da importância de serem modelos de um estilo de vida ativo e de oportunizarem os filhos a aumentar continuamente a atividade física.

\section{Papel da família na promoção da atividade física na infância ${ }^{83-86}$}

A família desempenha um papel crítico na formação da criança para a atividade física, pois as primeiras oportunidades e motivações para que alguém se torne fisicamente ativo começam em casa. O nível de atividade física dos pais relaciona-se positivamente com a atividade dos filhos na fase pré-escolar e na adolescência. Os estudos não demonstraram essa mesma relação com estudantes dos níveis fundamental e médio. A ajuda e o incentivo dos pais, quer na organização de atividades ou facilitando o transporte dos filhos e o acesso dos mesmos às atividades escolhidas, também apresentam relação positiva com a atividade física dos jovens.

\section{Recomendações à família $83-86$}

- Encorajar as crianças e os adolescentes para a prática regular de atividade física, ajudando-os a engajar-se em atividades prazerosas, na escola ou na comunidade;

- planejar e participar de atividades familiares que envolvam atividade física, em festas familiares, passeios ou viagens de férias, por exemplo; 
- ser modelo de um estilo de vida ativo, oferecendo aos filhos oportunidades de aumentar continuamente a atividade física;

- estabelecer limites de tempo para as atividades que não exigem dispêndio energético. Por exemplo, limitar a assistência a TV por no máximo duas horas diárias;

- reivindicar a criação de programas de atividade física de qualidade na escola e na comunidade;

- participar da escolha de locais para a realização de atividade física que possuam as condições físicas, climáticas, de segurança e de equipamentos necessárias.

\section{Papel da sociedade na promoção da atividade física na infância}

As escolas e a comunidade têm, potencialmente, a capacidade de melhorar a qualidade da promoção à saúde das crianças e adolescentes por meio da criação de programas e serviços que promovam a educação dos jovens e os incentivem a engajar-se em atividades físicas prazerosas, que possam incorporar-se indefinidamente ao seu estilo de vida. A maioria dos trabalhos de intervenção já realizados sobre promoção de atividade física em jovens foi desenvolvida nas escolas, com resultados promissores, demonstrando que a escola pode funcionar como o mais abrangente instrumento de educação para a saúde.

Considerando que as autoridades em saúde possuem o conhecimento dos efeitos benéficos da atividade física regular sobre a promoção da saúde, prevenção e reabilitação das doenças crônico-degenerativas, cabe às mesmas incluir em suas ações a realização de campanhas populacionais educativas sobre o tema, promover a incorporação pelos profissionais da saúde da prática de orientar a população sobre a importância da atividade física para a saúde e criar programas comunitários de educação para a saúde voltados para os jovens.

\section{Recomendações à comunidade ${ }^{83-86}$}

- Reinvidicar das autoridades competentes a criação, manutenção e avaliação de uma política de promoção à saúde que inclua a atividade física como um elemento a ser trabalhado em todos os níveis da educação, do desporto e da atenção à saúde;

- reinvidicar das escolas o cumprimento de decisões governamentais que incorporem a atividade física no processo educacional;

- participar dos programas de atividade física oferecidos à comunidade, incorporando um estilo de vida ativo que possa funcionar como modelo para crianças e adolescentes;

- propiciar o acesso de todas as crianças e adolescentes aos programas de atividade física, independentemente do seu grau de instrução, crença religiosa ou classificação econômica;

- estabelecer campanhas publicitárias que incentivem a prática de atividade física, em linguagem adequada para a compreensão de crianças e adolescentes;

- reivindicar a criação de áreas comunitárias destinadas à prática de atividade física, providas das condições físicas, climáticas e de segurança pertinentes.

\section{Recomendações à escola $a^{83-86}$}

- Cumprir o disposto no parágrafo terceiro do artigo 26 da LDB (no 9394 de 20 de dezembro de 1996), que diz: "a educação física, integrada à proposta pedagógica da escola, é componente curricular obrigatório da educação básica", considerando que a educação básica compreende o ensino infantil, fundamental e médio;

- oferecer programas de atividade física diária de qualidade, na grade curricular e extra-curricular, com possibilidade de escolha pelo aluno dentre vários tipos de atividade, ajudando-o a desenvolver o conhecimento e a confiança necessária para adotar e manter um estilo de vida fisicamente ativo;

- promover a educação em saúde como parte do conhecimento a ser adquirido pelo aluno ao longo da sua formação;

- identificar as necessidades específicas dos alunos, em especial daqueles que não têm predisposição para a prática esportiva;

- considerar as diferenças culturais e de gênero dos alunos na programação da atividade física na escola;

- incentivar e propiciar a participação dos alunos em atividade física dentro e fora da escola;

- não utilizar a atividade física como forma de punição e sim como uma prática agradável que faça parte da rotina diária do estudante;

- propiciar a formação dos professores em educação para a saúde, incorporando-a quando possível ao conteúdo específico da sua disciplina;

- propiciar aos profissionais de educação física o treinamento continuado em diferentes modalidades de atividade física, de forma a ampliar as possibilidades da mesma na escola;

- oferecer as instalações físicas, os equipamentos e os apetrechos necessários à realização de atividade física de boa qualidade;

- abrir a escola para programas de atividade física da comunidade;

- incluir os pais nos programas de atividade física extracurricular.

\section{Inatividade recreacional como fator de risco cardiovascular}

Embora não existam estudos que demonstrem que a realização de atividade física na infância à adolescência reduz a freqüência e a gravidade da doença cardiovascular na vida adulta, indivíduos menos ativos apresentam maior propensão ao hábito de fumar, à obesidade, a níveis 
elevados de pressão arterial, triglicerídeos, insulina e níveis mais baixos de HDL-colesterol. Há ainda evidências de que a atividade física nessa época da vida tem efeitos benéficos sobre o controle dos fatores de risco cardiovascular como a obesidade, a dislipidemia, a diabetes mellitus, o tabagismo e a hipertensão arterial sistêmica, bem como sobre a capacidade funcional aeróbica, a prevenção da osteoporose e a saúde psicológica dos seus praticantes ${ }^{87}$.

Estudos sobre a atividade física em crianças e adolescentes assumiram considerável importância nas últimas décadas, principalmente em função do aumento da prevalência do sobrepeso e da obesidade nestas faixas etárias, em todo o mundo e da hipótese de que isto tenha ocorrido graças à progressiva redução do nível de atividade física e da elevação do consumo de alimentos de alto teor energético. Estudos populacionais analisaram a atividade física realizada na escola e no lazer, bem como o tempo gasto em atividades sedentárias (televisão, computador ou telefone) e demonstraram que as crianças e adolescentes apresentam atualmente dispêndio energético diário abaixo da recomendação vigente e utilizam muito do seu tempo diário em atividades sedentárias ${ }^{88}$.

Considerando que a taxa de escolarização entre 5 e 17 anos no Brasil é, em média, de $81,7 \%$ (atingindo $95,7 \%$ na faixa etária de 7 a 14 anos) ${ }^{89}$ a escola é um veículo poderoso e eficiente, na implantação de programas de atividade física, por atingir a maior parte das crianças e adolescentes. Entretanto, como a maior parte da atividade física é realizada fora da escola é o período recreacional que termina por influenciar decisivamente no nível diário de atividade física realizado pelo jovem.

\section{Prevenção de Vícios na Prevenção da Aterosclerose}

\section{Qual é a criança que apresenta risco para o tabagismo?}

No Brasil, segundo dados da Conprev/Inca/MS e do Centro Brasileiro de Informações sobre Drogas (Cebrid), $90 \%$ dos fumantes experimentam o primeiro cigarro antes dos 13 anos de idade. Em 1989, foi realizado um estudo, em 10 capitais brasileiras, sobre o uso do tabaco entre estudantes do ensino fundamental e médio das escolas da rede estadual. Os resultados mostraram que $19,5 \%$ dos estudantes entrevistados já tinham fumado alguma vez na vida, enquanto que $15,9 \%$ tinham utilizado o tabaco no último ano e 10,5\% tinha-no utilizado na última semana ${ }^{90}$.

Variáveis socioculturais, ambientais, familiares, individuais, genéticas e psicofarmacológicas podem favorecer a iniciação ao tabagismo e/ou dificultar o seu abandono. Estudos mostram a importância de fatores de natureza psicossocial, como a dinâmica de interação familiar, imitação de modelos paternos e influência de terceiros, como parentes, colegas e amigos. Há ainda o feita pela indústria do tabaco e pelos meios de comunicação, entre outros fatores diversos ${ }^{90}$.

\section{Genética}

Estudos em gêmeos e animais mostram a influência substancial da genética para o desenvolvimento da dependência à nicotina. Embora não haja resultados definitivos,uma evidência consistente é a codificação dos genes do grupo de enzimas CYP, que levam ao aumento do metabolismo da nicotina e os genes DRD2 que regulam a função da dopamina. Mais estudos em relação a contribuição genética para o tabagismo podem levar, de uma forma mais expressiva, a estratégias mais efetivas no controle do tabagismo 90,91 .

\section{Co-morbidade psiquiátrica e tabagismo}

Pacientes com determinados transtornos psiquiátricos utilizam a nicotina como medicação, por isso ressentem-se mais com a sua abstinência. Estatísticas americanas mostram que $50 \%$ dos pacientes psiquiátricos fumam, comparados com $25 \%$ da população geral e $50 \%$ da população geral consegue parar de fumar, enquanto somente $15 \%$ dos pacientes psiquiátricos o fazem. 0 transtorno do déficit de atenção - hiperatividade (TDAH) é um transtorno crônico que afeta crianças e adolescentes, colocando-os em situação de risco incluindo o uso de substâncias psicoativas, sendo o tabagismo a mais prevalente.Uma hipótese para explicar a alta prevalência de tabagismo nestes pacientes é a automedicação. A ação da nicotina sobre a capacidade de concentração, atenção e memória, faz com que seja uma substância benéfica na superação dos sintomas relacionados ao TDAH. Esta associação alerta que a prevenção do tabagismo tem uma importância particular nos pacientes com história de TDAH. Outras co-morbidades associadas mais freqüentemente ao tabagismo são a depressão,os trantornos de ansiedade e a esquizofrenia ${ }^{90,92}$.

\section{Fumo passivo}

Os não fumantes que se expõem à poluição tabagística ambiental são chamados fumantes passivos ou involuntários. 0 efeito do tabagismo passivo é tanto mais intenso quanto menos ventilado for o ambiente considerado. A poluição tabagística ambiental (PTA), apresenta dois componentes que são: a fumaça exalada pelo fumante (corrente primária) e a fumaça da corrente secundária, que é o principal componente da PTA, pois é formada durante $96 \%$ do tempo total da queima dos derivados do tabaco. A PTA é particularmente mais nociva às crianças pela maior vulnerabilidade de suas vias aéreas e sobretudo porque as de mais baixa idade permanecem maior tempo confinadas em seus domicílios ${ }^{93}$.

\section{Efeitos da PTA}

Os sintomas imediatos mais freqüentes, originados dos efeitos agudos da PTA são irritação nos olhos, manifestações nasais, cefaléia e tosse. Os indivíduos atópicos 
são mais sensíveis à PTA, apresentando exacerbação de seus quadros alérgicos respiratórios. As crianças, principalmente as de baixa idade, são muito prejudicadas pela PTA, proveniente do tabagismo dos pais. Vários estudos já mostraram a relação entre tabagismo passivo e doenças como a pneumonia, bronquite aguda, bronquiolite, broncopneumonia, infecção do ouvido médio e exacerbação de crise de asma. A síndrome da morte súbita infantil é mais freqüente nos casos que as mães fumaram durante a gestação e também foi descrita em crianças expostas ao tabagismo dos pais após o nascimento e não durante a gestação. $A$ exposição de crianças previamente assintomáticas à PTA de mães fumantes de pelo menos 10 cigarros-dia resulta em 8.000 a 26.000 novos casos de asma anualmente. Nestes casos a concentração de carboxi-hemoglobina pode elevar-se a $50 \%$. Outros estudos mostram que crianças de zero e um ano de idade apresentam quase o dobro de episódios de bronquite crônica e pneumonia se houver um fumante na casa e quase o triplo se houver dois fumantes ${ }^{93}$.

\section{O fumo e a mulher em idade fértil}

A ação do fumo sobre os circundantes do fumante pode ser exercida, através do sangue, no caso da gestante e através do leite materno, no caso da nutriz. Os elementos tóxicos do fumo presentes na circulação materna, atravessam a placenta. Essas substâncias provocam no feto distúrbios de consequências imediatas e tardias. Complicações com a placenta, vasoconstricção, anoxia, aumento da frequência cardíaca, dificuldade dos movimentos torácicos repercutem de modo desfavorável no desenvolvimento fetal e de seus centros nervosos respiratórios. Eleva-se o risco de abortos espontâneos, natimortalidade, de mortalidade neonatal e prematuridade, baixo peso ao nascer, menor estatura em idade escolar e relativo atraso mental em relação à habilidade geral, compreensão à leitura e à matemática. Também verificouse maior freqüência de escolares com QI abaixo do previsto nos casos em que as mães fumaram durante a gestação. Estudos da urina de lactentes filhos de mães fumantes demonstraram taxas elevadas de cotinina,o metabólito ativo da nicotina, após cada mamada ${ }^{93}$.

\section{Papel da família e professores na prevenção do tabagismo $^{90}$}

Quanto mais cedo as crianças tiverem acesso a informações sobre os males causados pela indústria do fumo, mais distantes elas estarão da aceitação social do cigarro. Por isto,a escola é o lugar ideal para programas de educação em saúde por uma melhor qualidade de vida. O Ministério da Saúde, através do Inca-Conprev, desenvolve um programa, o Saber Saúde, em unidades escolares, com material especificamente elaborado para que os educadores abordem de forma adequada o público infanto-juvenil. Esses programas devem incluir informações sobre as conseqüências sociais e efeitos psicológicos a curto prazo da utilização do tabaco, as influências sociais e afetivas provocadas pelos pais fumantes e pela mídia de cigarros e treinamento de habilidades de recusa. Outra atitude importante é a criação nas escolas, principalmente dentro das salas de aula, de um ambiente livre do cigarro e de sua publicidade.

Os profissionais que atendem crianças devem ser orientadores, fornecendo conselhos sobre o potencial do problema do tabagismo com mensagens adequadas para cada idade e fase de desenvolvimento. Orientações promovidas por pais, professores e profissionais da área de saúde podem influenciar mudanças de atitude na comunidade, através da intervenção quanto ao início da utilização do fumo.

\section{Papel do pediatra frente aos pais e crianças fumantes $^{90}$}

Indivíduos entre 20 e 35 anos de idade costumam freqüentar ambientes médicos apenas para acompanhar os filhos. Não falar sobre o tabagismo pode ser interpretado pelos pais como um aval ao cigarro. Os médicos, principalmente os pediatras e médicos de adolescentes, têm um papel importante na prevenção do tabagismo em seus pacientes e na proteção contra a exposição passiva à fumaça do cigarro, principalmente nas faixas etárias mais jovens. Dois grupos etários mostram diferentes perspectivas de abordagem: Do nascimento aos quatro anos e dos cinco aos doze anos. As seguintes orientações são preconizadas pela CONPREV/INCA:

Do nascimento aos quatro anos (lactância e primeira infância) ${ }^{90}$

- Pergunte aos pais sobre o uso de cigarros no lar e no meio ambiente da criança. Procure saber se ela sofre alguma exposição freqüente à fumaça de cigarros.

- Aconselhe todos os pais fumantes a pararem de fumar. Informe-os acerca da relação entre a exposição involuntária das crianças à fumaça do cigarro e sobre as infecções e alergias respiratórias que geram um grande número de hospitalizações. Ressalte a importância em garantir que crianças cresçam e se desenvolvam em um ambiente livre de fumaça.

- Prepare ou encaminhe os pais fumantes para abandonarem o fumo, identificando estratégias eficazes para esta interrupção e ofereça acompanhamento.

- Acompanhe e se interesse pela evolução do tabagismo nessas famílias, durante as consultas de retorno.

\section{Dos cinco aos doze anos (infância tardia) ${ }^{90}$}

É importante alertar os pais sobre o aumento da consciência da criança a respeito do mundo a sua volta. O início do tabagismo pode começar precocemente, em torno dos cinco anos de idade, principalmente na zona rural e em 
regiões onde se planta fumo, embora, de um modo geral, o início do tabagismo ocorra mais freqüentemente em préadolescentes. A chance de uma criança se tornar fumante está diretamente ligada aos modelos de identificação, isto é, ao fato de ter pais, irmãos e amigos que fumam e que apresentam atitudes positivas em relação ao tabagismo. Vale lembrar que as crenças e as práticas dos pais em relação ao tabagismo influenciam as crianças, devendo ser encorajados a reavaliarem seus comportamentos.

A participação da criança na discussão sobre o tabagismo e a utilização do fumo deve ser incentivada. 0 envolvimento ativo da criança nos cuidados com sua própria saúde a ajuda a ter responsabilidade e autocontrole sobre decisões que a conduzam a comportamentos saudáveis. 0 desenvolvimento da assertividade (capacidade de dizer "não") da criança deve ser estimulado, para que esta se sinta mais capaz para fazer escolhas. Isto favorece a autoestima da criança, o seu amadurecimento emocional e além de uma maior capacidade para lidar com a frustração.

- Pergunte à criança se ela fuma ou se já fumou e sobre a utilização de derivados do tabaco por amigos ou familiares. Procure descobrir se ela sabe o que é tabaco e conhece os prejuízos por ele causados. Pergunte freqüentemente sobre o desempenho escolar da criança, pois o tabagismo pode reduzir seu rendimento e se há fumantes no ambiente escolar.

- Aconselhe as crianças que estejam experimentando cigarros a interromperem imediatamente e as que ainda não experimentaram a recusarem as ofertas. Alerte sobre os efeitos do tabagismo a curto prazo: impregnação de roupas e cabelo por odor desagradável, escurecimento dos dentes, respiração difícil, redução do desempenho esportivo, escolar e dependência de uma droga - a nicotina. Os pais devem ser alertados sobre como funcionam como modelos de identificação e sobre o tabagismo passivo. Também precisam desestimular o uso pelos filhos de produtos relacionados ao cigarro, como doces em forma de cigarro, roupas com logomarcas de cigarros, pois o consumo destes objetos ajuda a promover o tabagismo.

- Prepare a criança para ser cada vez mais responsável sobre seu comportamento saudável. Deve-se parabenizar as crianças que não utilizam o tabaco e orientar as crianças que fumam ou sofrem forte infuência de modelos comportamentais do meio ambiente que desenvolvam habilidades de recusa, importância do direito de optar, dizendo "não" e valorizando a auto-estima.

- Acompanhe as crianças que estiverem fumando, marcando visitas mais freqüentes ou encaminhando para programas específicos de ajuda que, se possível, devem estar integrados à escola da criança, o mesmo devendo ser feito com os pais fumantes.

\section{Educação desde a pré-escola sobre os malefícios das drogas ${ }^{90}$}

Os programas de prevenção existentes são dirigidos apenas às crianças do ensino fundamental e médio. 0
Instituto Nacional do Câncer desenvolve, desde 1998, o Programa "Saber Saúde", com o objetivo de informar e educar as crianças nas escolas brasileiras quanto ao tabagismo e aos outros fatores de risco de câncer. Em relação à pré-escola, entretanto, são necessários programas específicos associados a um seguimento de longa data, com atividades lúdicas como histórias, teatrinho de fantoches, teatro infantil, contadores de histórias, etc.

\section{Práticas na manutenção do comportamento na adolescência ${ }^{90}$}

Diferente do que ocorre com os adultos, um dos aspectos do tabagismo entre os adolescentes é que seus hábitos são irregulares. Esta característica pode ser favorável para iniciativas e estratégias de prevenção. Entretanto, muitos jovens viciam-se também em álcool e outras drogas. No contato com o adolescente, é importante estabelecer um vínculo de confiança, respeito e sigilo, procurando entender que adolescência significa ruptura, auto-afirmação e questionamento. Freqüentemente, o jovem começa a fumar nesta fase por curiosidade, imitação dos pais e amigos, para expressar independência, superar timidez e adquirir segurança. Há também a necessidade de seguir algum ritual, reforçando a dependência comportamental. Alguns fatores contribuem para o aumento cada vez maior do consumo de tabaco entre os adolescentes:

- acreditam que podem deixar quando quiserem;

- utilizam como forma de contestação dos valores familiares e sociais;

- acreditam que parecem mais atraentes;

- falta de perspectiva futura, escassez de modelos de identificação, carência afetiva e insatisfação: o tabaco se torna interessante na busca de novos prazeres, alegria e emoção;

- mensagens na mídia ligando o cigarro ao sucesso (exemplo: corridas de carros).

Neste grupo populacional, as campanhas contra o tabaco puramente informativas surtem pouco efeito. São mais efetivos os esforços no sentido de orientar os adolescentes a resistir às pressões sociais que os levam a fumar. Embora o conhecimento dos riscos do tabagismo sobre a saúde seja um importante fator de rejeição ao fumo, não é suficiente para impedir que um indivíduo utilize cigarros. Entre os adolescentes, a afetividade é um dos fatores principais na escolha do uso dos derivados do tabaco. Os jovens que pertencem a grupos de amigos que fumam estão mais propensos a fumar e aqueles cujos amigos não são fumantes provavelmente não o serão. 0 alívio para o estresse originado das demandas de ajustamento a um grupo afetivo, aliado a certas características de auto-imagem (rebeldia, sociabilidade e precocidade) também tem sido associado a uma tendência para o fumo. No caso das mulheres, o tabagismo é um meio utilizado para manter o peso corporal, já que o "culto ao corpo" é tão estimulado pela 
sociedade. Um outro dado importante é que, segundo a OMS, o tabagismo é considerado a porta de entrada para o vício em outras drogas.

Na literatura, existem poucos estudos sobre prevenção do tabagismo na adolescência.As campanhas para adultos, modificadas para adolescentes, não apresentam resultados promissores. Aconselhamentos breves e reiterados aos jovens fumantes, durante atendimento por profissionais da área de saúde, principalmente para adolescentes com doenças relacionadas ao tabaco, podem ter impacto na cessação do tabagismo.Por outro lado, intervenções breves na escola, têm efeito a curto, mas não a longo prazo. Uma revisão realizada por Sowden e Arblaster, baseada em um pequeno número de estudos, mostrou que campanhas antitabaco por meio da mídia poderiam influenciar positivamente jovens com menos de 25 anos.

\section{Prevenindo o uso do tabaco na prática clínica ${ }^{90}$}

É preciso que o médico estabeleça um perfil de risco do tabagismo na adolescência, baseando-se em alguns preditores importantes, representados na Tabela IX. As respostas podem orientar o clínico onde intervir para aumentar o nível de prevenção.

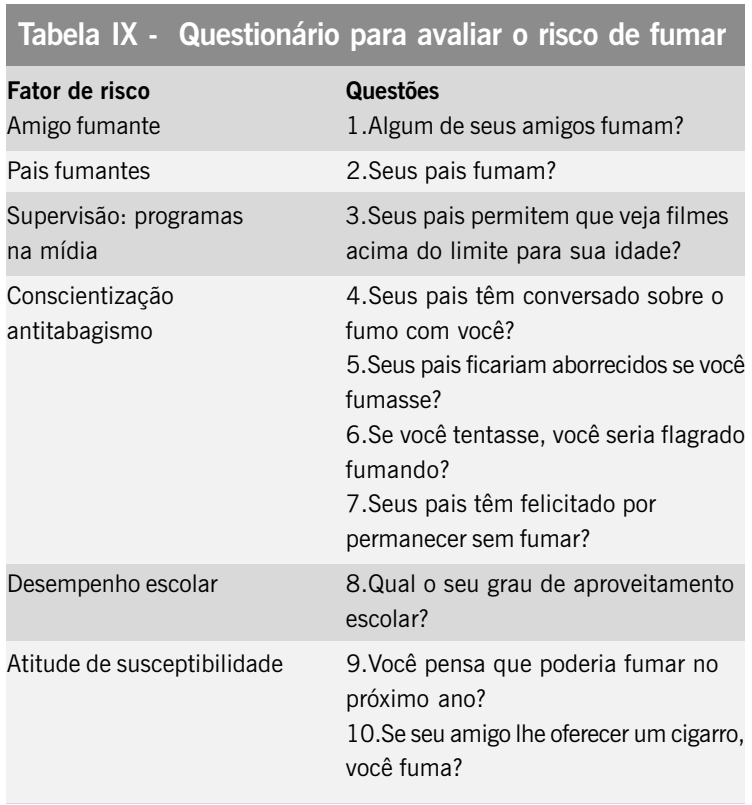

As características peculiares dos adolescentes podem ser exploradas de forma positiva pelas ações de controle do tabagismo. Informações, como dificuldades respiratórias, escurecimento dos dentes ou redução da aptidão atlética, devem ser expostas durante boa parte da consulta médica. $\mathrm{O}$ aconselhamento constante é importante, pois, embora os adolescentes se motivem mais a deixar o cigarro que os adultos, as recaídas também são freqüentes.

\section{Estratégias de tratamento}

Os profissionais da área de saúde devem encorajar e apoiar a interrupção do hábito do tabagismo, principalmente entre os pais de crianças e adolescentes, pelo duplo impacto que esta atitude causa no tratamento e na prevenção do tabagismo ativo e passivo nas crianças. 0 jovem fumante, especificamente, deve ser tratado de maneira lenta e progressiva, a cada consulta.

A terapia cognitivo-comportamental por meio de grupos terapêuticos é a modalidade de escolha para os jovens fumantes. Os conteúdos do aconselhamento devem se adequar ao público jovem, com dinâmica, linguagem e materiais didáticos voltados para o adolescente. Deverão ser enfatizadas as atividades físicas, perda da capacidade de escolha provocada pela dependência, os aspectos ilusórios da propaganda do cigarro, os cuidados com o corpo, com a estética e o desempenho sexual.

\section{Tratamento medicamentoso}

Faltam estudos randomizados e controlados com placebo, sobre a utilização da terapia de reposição com nicotina (TRN) e com a bupropiona para crianças e adolescentes. Estes medicamentos não estão autorizados para uso em menores de 16 anos na Inglaterra e nos EUA. Por essas razões, existe a necessidade de se desenvolver métodos alternativos para apoiar jovens fumantes ${ }^{94}$.

\section{Aspectos Psicológicos na Prevenção da Aterosclerose}

Os aspectos psicológicos interagem com outros fatores, resultando em um círculo vicioso que pode ter como conseqüência a doença coronariana ${ }^{95}$. Há cinco classes de fatores psicológicos que podem contribuir para a patogênese da doença arterial coronariana: depressão, ansiedade, características de personalidade, isolamento social e estresse crônico. Entre os mecanismos envolvidos no desenvolvimento da aterosclerose estão incluídas a ativação excessiva do sistema nervoso simpático e a ativação de plaquetas.

\section{Formação da personalidade na infância}

O ideal é promover intervenções profiláticas que garantam às crianças a aquisição de um estilo de vida que contemple escolhas mais saudáveis. As intervenções na infância e na adolescência têm maior probabilidade de sucesso, pois os hábitos de vida ganham força e se sedimentam à medida que são repetidos ${ }^{96}$.

\section{Depressão mascarada e comportamento de risco (fumo, drogas ilícitas)}

Os sintomas de depressão variam desde uma postura física e expressão facial tristes, agitação motora e hiperatividade, até comportamentos agressivos e autodestrutivos. Comportamentos de risco, como tabagismo, consumo de bebidas alcoólicas, promiscuidade sexual, uso de drogas ilícitas, vandalismo e atos agressivos, muitas vezes, são mecanismos compensatórios de estados emocionais 
comprometidos pela depressão e pelo estresse emocional ${ }^{97}$. As ações de prevenção contra os fatores desencadeantes da depressão, como falta de objetivos de vida, sensação de inutilidade frente ao mundo, falta de perspectiva, falta de estratégias para lidar com as tensões da vida e desconhecimento do valor de hábitos de vida saudáveis para a manutenção da saúde, podem colaborar para a redução do sedentarismo, do uso indevido de drogas ilícitas e do tabagismo. Os Quadros III e IV descrevem os sintomas mais comuns e os indicadores de depressão mascarada em crianças e adolescentes.

\section{Quadro III - Indicadores de depressão mascarada em crianças \\ Postura física rígida; expressão facial neutra mesmo em retratos; agitação motora; negativismo; comportamentos autodestrutivos; destruição de brinquedos; choro sem razão aparente; dificuldade de concentração; polilalia; agressividade contra colegas, pais e animais; acidentes freqüentes; morte de colega ou irmão nos últimos 6 meses.}

\section{Quadro IV - Indicadores de depressão mascarada em adolescentes}

Comportamentos de risco; agressividade verbal ou física contra pais ou avós; brigas com colegas; dificuldades em manter um namoro; tabagismo; uso de drogas ilícitas; uso excessivo de bebidas alcoólicas; promiscuidade sexual; vandalismo; abuso verbal ou físico de professores; auto-agressão; não socialização com colegas da mesma idade; queixas sobre falta de energia e desânimo; interesses restritos; acidentes freqüentes; morte de colega ou irmão nos últimos 6 meses.

\section{A auto-estima e a adoção de hábitos saudáveis}

Os programas de prevenção de aterosclerose devem enfocar o controle da obesidade e das disfunções metabólicas, por meio de mudanças de hábitos alimentares e aumento da atividade física. Nesta faixa etária, além de inúmeros fatores da vida moderna, o estresse emocional associado à preferência por alimentos doces e gordurosos, representa um obstáculo à modificação no estilo de vida. A intervenção psicológica comportamental é atualmente reconhecida como a que oferece maiores índices de sucesso quanto a mudanças de hábitos de vida, redução de níveis de estresse emocional, adesão a programas de atividade física, modificação alimentar, redução da obesidade, aumento de atividades físicas nas horas de lazer, menor isolamento e maior adesão a tratamentos medicamentosos ${ }^{98}$.

Um aspecto que deve ser considerado é a forma de instituição dos programas que têm por objetivo a redução da obesidade infantil. Embora esteja bastante clara a necessidade dos mesmos, deve-se evitar o desenvolvimento de insatisfação com a imagem corporal, baixa auto-estima, transtorno dismórfico corporal e até bulimia e anorexia ${ }^{41}$.

\section{O estresse como causa de fatores de risco para a aterosclerose}

O estresse foi descrito como um dos possíveis fatores contribuintes para o desenvolvimento da aterosclerose, etiologia de outros fatores de risco, como a obesidade, depressão, hipercolesterolemia e o sedentarismo ${ }^{99}$. A incidência do estresse infantil é bastante preocupante. Descrevem-se índices de $23 \%$ de estresse em escolares na primeira série do ensino fundamental e cerca de $65 \%$ em alunos do $3^{\mathrm{a}}$ série do ensino médio, chegando a $83 \%$ no período pré-vestibular ${ }^{100}$. O Quadro $V$ mostra os sintomas de estresse mais freqüentes em crianças e o Quadro VI lista os sintomas em adolescentes.

\section{Quadro V - Sintomas de estresse em crianças $^{100,101}$}

Sintomas psicológicos: terror noturno; introversão súbita; medo excessivo; agressividade ou impaciência; choro excessivo; pesadelos; ansiedade; dificuldades interpessoais; desobediência inusitada; depressão, desânimo; hipersensibilidade; insegurança.

Sintomas físicos: dor de barriga, azia; diarréia, náusea; tique nervoso; dor de cabeça; mãos frias e suadas; hiperatividade; enurese noturna; gagueira; tensão muscular; bruxismo; taquicardia; dores nas pernas e braços.

$\begin{aligned} & \text { Quadro VI - Sintomas de estresse em } \\ & \text { adolescentes } \\ & \text { (00,101 }\end{aligned}$
Aumento substancial ou perda de apetite; cansaço constante; tensão
muscular; irritabilidade excessiva; ansiedade ou angústia diária;
vontade de não fazer nada; dor de cabeça; comportamento de risco;
agressividade; queda de notas na escola; hiperatividade; inquietação;
uso de álcool ou de drogas ilícitas; promiscuidade sexual.

Considerando-se a associação entre estresse agudo ou crônico e doenças físicas e mentais, torna-se necessário implementar ações dirigidas para a família e para a sociedade com o objetivo de aliviar a tensão emocional à qual crianças e adolescentes estão expostos.

\section{Tratamento dos Fatores de Risco}

\section{Dislipidemias}

Em 2002, a American Heart Association, com base nas recomendações do Committee on Atherosclerosis, Hypertension, and Obesity in the Young (AHOY) ${ }^{80}$, sugeriu um algorítmo para tratamento das dislipidemias de acordo com o risco individual e perfil lipídico obtido (Figura 2). Desta forma, todas as crianças com LDL-C > $130 \mathrm{mg} / \mathrm{dL}$ devem ser acompanhadas. A primeira opção deve ser a dieta com baixos teores em gordura saturada e colesterol. As recomendações para o uso de fármacos são reservadas, exclusivamente, para as crianças com idade $>10$ anos que apresentam níveis de LDL-C persistentemente elevados, a despeito da orientação nutricional. Os valores de referência do LDL-C para a intervenção com hipolipemiantes dependem dos fatores de risco presentes, da história familiar e da magnitude da elevação do LDL-C.

Tratamento farmacológico na infância e adolescência

O tratamento farmacológico tem sido indicado preferencialmente para as situações de maior risco e de 


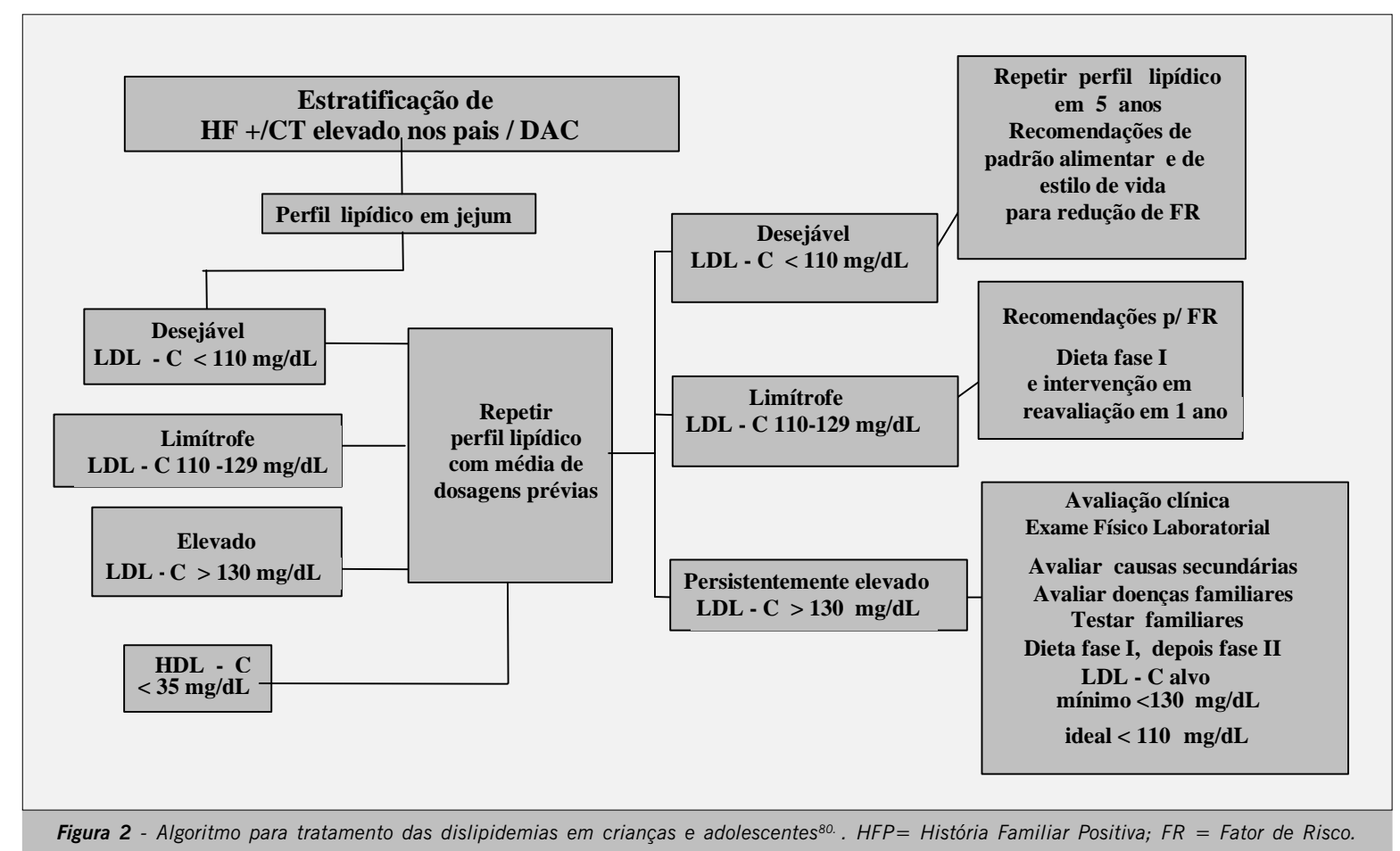

falha das modificações do estilo de vida para se atingir o nível ideal de LDL-C, de acordo com a história familiar e fatores de risco presentes ${ }^{80}$. A Tabela $X$ apresenta os pontos de corte para a utilização de drogas hipolipemiantes em crianças. (Grau de Recomendação Ilb, Nível de Evidência D).

Tabela X - Valores de referência para tratamento

farmacológico hipolipemiante em crianças com

idade $\geq 10$ anos, conforme a condição clínica ${ }^{80}$

\begin{tabular}{ll}
\hline $\mathrm{LDL}-\mathrm{C}(\mathrm{mg} / \mathrm{dL})$ & Condição clínica \\
$>190$ & Dislipidemia de base genética \\
$>160$ & História familiar de $\mathrm{DAC}$ prematura ou dois \\
& ou mais fatores de risco (HDL-c $<35 \mathrm{mg} / \mathrm{dL}$, \\
& fumo, hipertensão arterial, obesidade, diabetes)
\end{tabular}

\section{Sequestrantes de ácidos biliares (resinas)}

O colestipol e a colestiramina são as resinas aprovadas para uso em crianças ${ }^{102,103}$. Por diminuir a absorção intestinal de ácidos biliares, aumentam a expressão de receptores hepáticos para a $L D L$, determinando redução do colesterol sérico. As reduções no LDL-C são relativamente modestas, obtendo-se diminuições ao redor de $19 \%$ em crianças e adolescentes com hipercolesterolemia familiar após o uso de colestiramina ( $8 \mathrm{~g} / \mathrm{dia}$ ) ou de colestipol (10 g/dia) ${ }^{104}$, este último não disponível no Brasil. Doses mais elevadas aumentam a incidência de efeitos adversos gastrintestinais e não acentuam a redução do colesterol, devido a mecanismos compensatórios, como o aumento da síntese de colesterol hepático. As resinas podem aumentar os níveis de triglicérides (maior síntese de VLDL) e diminuir a absorção de vitaminas lipossolúveis e de ácido fólico. Para aumentar a efetividade das resinas, sua associação com a ezetimiba também foi testada e esta dupla via intestinal de interferência no metabolismo do colesterol (absorção de sais biliares e de colesterol) mostrou benefícios adicionais ${ }^{105}$.

\section{Vastatinas}

A experiência com as vastatinas é limitada pela falta de estudos de longo prazo para a avaliação de desfechos clínicos e segurança. Estudos com lovastatina, sinvastatina, pravastatina e atorvastatina mostraram reduções expressivas do LDL-C, além de boa tolerabilidade. Todos estes fármacos têm sido usados nos EUA e os dois últimos já possuem indicação para seu uso no Brasil, especialmente em crianças com idade $>10$ anos, inclusive para as meninas após a menarca. Entretanto, são contra-indicados durante a gestação e as adolescentes e mulheres em idade fértil não devem fazer uso das vastatinas sem uma adequada contracepção, pois seu uso pode estar associado com malformações, especialmente do sistema nervoso central. As doses empregadas variam conforme o nível basal de LDL-C e, nas formas mais graves de hipercolesterolemia familiar, tem sido sugerida a associação de vastatina com resina ou, mais recentemente, com ezetimiba. As vastatinas podem induzir a aumento discreto e transitório das enzimas hepáticas e miosite, sendo recomendada a monitoração das enzimas hepáticas (ALT e/ou AST) e da creatinofosfoquinase (CK), especialmente na presença de sintomas musculares ${ }^{102,103}$.

\section{Ezetimiba}

Trata-se de inibidor específico da absorção de colesterol. É empregado na dose de $10 \mathrm{mg} /$ dia e não apresenta o sintoma de desconforto gastrintestinal 
observado com as resinas. É usado, preferencialmente, em associação com vastatina, pela vantagem de duplo mecanismo redutor do colesterol. Seu uso em crianças com idade $>10$ anos já foi aprovado nos EUA, para hipercolesterolemia grave. A efetividade da atorvastatina e da sinvastatina em associação com a ezetimiba foi testada em portadores de hipercolesterolemia familiar homozigótica. Mesmo neste grupo de pacientes, esta associação foi bem tolerada e promoveu importante redução no LDL-C, pelo menos $20 \%$ maior do que obtido apenas com as vastatinas ${ }^{106}$. Na grave hipercolesterolemia autossômica recessiva, há relato do uso da rosuvastatina em associação com a ezetimiba permitindo a normalização do LDL-C, regressão de xantomas e eliminação da necessidade da aférese de LDL. Entretanto, a experiência com esta associação ainda é limitada, especialmente no perfil de segurança de longo prazo, e estes casos devem, se possível, ser encaminhados para um centro de referência em dislipidemias ${ }^{102,103}$.

A sitosterolemia, rara alteração do gene ABCG5/G8, determina hiperabsorção de esteróis da dieta, marcada elevação plasmática e tecidual de sitosterol e dos níveis plasmáticos de campesterol, associando-se ao desenvolvimento de aterosclerose prematura. Como a ezetimiba inibe tanto a absorção intestinal de colesterol como dos esteróis vegetais, o uso deste fármaco determina uma efetiva redução da sitosterolemia ${ }^{107}$.

\section{Fibratos e ácido nicotínico}

O uso de fibratos em crianças e adolescentes foi descrito em pequenos estudos, observando-se reduções moderadas de colesterol total e LDL-C, com boa tolerabilidade. Seu uso nesta faixa etária ainda aguarda maior experiência. 0 ácido nicotínico não tem sido recomendado para crianças e adolescentes, devido ao potencial para efeitos adversos e ausência de dados relativos a sua tolerabilidade nesta faixa etária102,103.

\section{Nutracêuticos e suplementos alimentares}

Os ácidos graxos ômega-3 podem contribuir para uma redução na trigliceridemia e os estanóis de plantas e a proteína da soja podem promover reduções discretas no LDL-C. (Grau de Recomendação Ilb, Nível de Evidência D). Os estanóis e fitosteróis são contra-indicados na presença de sitosterolemia ${ }^{102,103}$.

\section{Hipertensão arterial sistêmica}

0 tratamento medicamentoso da hipertensão arterial nessa faixa etária ainda é controverso e a questão mais relevante diz respeito à utilização de terapia farmacológica por tempo prolongado e os seus possíveis efeitos sobre o desenvolvimento físico e a qualidade de vida desses indivíduos. Mais do que em qualquer outra faixa etária, justifica-se plenamente nesses casos a adoção de medidas saudáveis nos hábitos de vida como forma de combater os fatores associados que podem influenciar na elevação da pressão arterial ${ }^{60}$.

\section{Modificações terapêuticas no estilo de vida}

$\mathrm{Na}$ criança e no adolescente, apesar das evidências limitadas, seus benefícios sobre a saúde em geral recomendam a implementação para todas as crianças com

\begin{tabular}{|c|c|c|c|c|}
\hline Classes de drogas & Fármacos e doses diárias & Efeito nos lípides & Efeitos colaterais descritos & Contra-indicações \\
\hline $\begin{array}{l}\text { Vastatinas } \\
\text { Meninos-Tanner II } \\
\text { Meninas-pós } \\
\text { menarca }\end{array}$ & $\begin{array}{l}\text { Lovastatina }(10-40 \mathrm{mg}) \\
\text { Pravastatina }(5-40 \mathrm{mg}) \\
\text { Simvastatina }(5-40 \mathrm{mg}) \\
\text { Atorvastatina }(10-20 \mathrm{mg})\end{array}$ & LDL $\downarrow 17-45 \%$ & 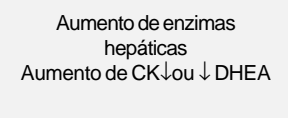 & $\begin{array}{l}\text { Absoluta: Doença hepática } \\
\text { ativa ou crônica } \\
\text { Relativa: Concomitante uso } \\
\text { de certas drogas }\end{array}$ \\
\hline $\begin{array}{l}\text { Resinas } \\
\text { Sem restrição de idade }\end{array}$ & $\begin{array}{c}\text { Colestiramina }(4-16 \mathrm{~g}) \\
\text { Colestipol }(5-20 \mathrm{~g}) \\
\text { Coleveselam }(2,6 \mathrm{a} 3,8 \mathrm{~g})\end{array}$ & $\begin{array}{c}\text { LDL } \downarrow 15-30 \% \\
\text { HDL } \uparrow 3-5 \% \\
\text { TG não altera ou aumenta }\end{array}$ & $\begin{array}{l}\text { Distúrbios Gl, constipação, } \\
\text { redução de absorção de outros } \\
\text { fármacos e vitaminas } \\
\text { lipossolúveis }\end{array}$ & $\begin{array}{c}\text { Absoluta: Disbetali- } \\
\text { poproteinemia } \\
\text { TG }>400 \mathrm{mg} / \mathrm{dL} \\
\text { Relativa: } \mathrm{TG}>200 \mathrm{mg} / \mathrm{dL}\end{array}$ \\
\hline $\begin{array}{l}\text { Inibidores absorção } \\
\text { do colesterol } \\
>10 \text { anos }\end{array}$ & Ezetimiba & $\begin{array}{c}\text { LDL } \downarrow 17-20 \%, \\
\text { monoterapia } \\
\text { LDL } \downarrow \text { até em } 60 \%, \\
\text { associada às vastatinas }\end{array}$ & $\begin{array}{l}\text { Comparáveis ao placebo, } \\
\text { em monoterapia } \\
\text { Podem aumentar a síntese } \\
\text { de colesterol }\end{array}$ & $\begin{array}{l}\text { Absoluta: Doença } \\
\text { hepática e renal graves } \\
\text { Relativa: Não há }\end{array}$ \\
\hline $\begin{array}{l}\text { Nutracêuticos e } \\
\text { suplementos } \\
\text { alimentares }\end{array}$ & - & $\begin{array}{c}\text { TG } \downarrow \\
\text { LDL } \downarrow \text { até } 14 \% \\
\text { LDL } \downarrow 5-10 \%\end{array}$ & - & - \\
\hline $\begin{array}{l}\text { Ácidos graxos } \\
\text { ômega } 3\end{array}$ & 2- $4 \mathrm{~g} / \mathrm{dia}$ & - & $\uparrow$ LDL- C & sitosterolemia \\
\hline Estanóis de plantas & $2,3 \mathrm{~g} / \mathrm{d}$ & - & - & - \\
\hline Soja & $25 \mathrm{~g} / \mathrm{dia}$ & - & - & - \\
\hline
\end{tabular}


PAS e/ou PAD maior ou igual ao percentil 95, em 3 ou mais ocasiões (hipertensão arterial estabelecida) ou com PAS e/ou PAD maior ou igual ao percentil 90 e menor que o percentil 95 (pré-hipertensão) um padrão dietético saudável (rico em frutas, vegetais, grãos integrais, carne branca e restrito em gordura saturada ( $<10 \%$ calorias/ dia), colesterol (<300mg/dia), açúcar e sal $(<6 g /$ dia $)$ ). Para o grupo de indivíduos situados na faixa de PA classificada como pré-hipertensão, a recomendação é de que devam ser iniciadas as medidas de intervenção sobre o estilo de vida como passo inicial do tratamento (Grau de Recomendação Ila, Nível de Evidência D) ${ }^{60,83}$.

Em relação ao sal, embora a restrição da sua ingesta possa afetar apenas modestamente a PA nessa faixa de idade (1 a $3 \mathrm{mmHg}$ de redução), dados de estudo clínico controlado demonstraram que a redução do aporte de sal na infância foi capaz de afetar a PA na adolescência. Diante desses fatos, a ingesta de sal deve ser de $1,2 \mathrm{~g}$ por dia dos 4 aos 8 anos e 1,5 g/dia após esta idade ${ }^{60,108}$ (Grau de recomendação Ila, Nível de Evidência D).

Em relação ao potássio, cálcio e magnésio, as evidências apontam para uma associação entre o aumento da ingesta com menores valores de PA. Entretanto, estas associações são ainda insuficientes para suportar a recomendação da suplementação alimentar desses nutrientes (Grau de Recomendação III, Nível de Evidência D). A orientação nutricional supervisionada pode ser útil na elaboração do esquema alimentar aumentando a chance de adesão às medidas propostas ${ }^{60,108}$ (Grau de Recomendação Ila, Nível de Evidência D).

Deve ser enfatizada a redução do peso corporal, pois esta condição apresenta uma forte correlação com a elevação da PA 1,2,5,10-12 (Grau de Recomendação I, Nível de Evidência D). Estudos clínicos conduzidos em crianças demonstraram que o "tracking" da PA se associa fortemente com o peso, durante a vida ${ }^{(60 ; 110)}$. De forma inversa, a perda de peso tem sido demonstrada como uma medida bastante efetiva na redução da PA, além de também diminuir a sensibilidade ao sal e a resistência à insulina e reduzir outros fatores de risco associados com a elevação da pressão arterial como a dislipidemia. Uma perda de peso da ordem de $10 \%$ é capaz de reduzir a PA em 8 a $12 \mathrm{~mm} \mathrm{Hg}$ em adultos ${ }^{60,110}$. Pelas razões apontadas, a presença de sobrepeso/obesidade é levada em consideração na decisão clínica do tratamento da HAS e foi uma variável incluída no algoritmo de avaliação e tratamento da HA em crianças(Grau de Recomendação I, Nível de Evidência D).

A implementação de atividade física regular deve também ser enfatizada e é um importante componente do tratamento da obesidade em crianças. Recomenda-se exercício com duração de uma hora por dia, que as atividades sejam divertidas e que o tempo de lazer não seja sedentário (menos que 2h/dia) ${ }^{111}$ (Grau de Recomendação I, Nível de Evidência D). 0 hábito de fumar deve ser expressamente combatido, envolvendo inclusive os adultos fumantes próximos à criança ou ao adolescente ${ }^{83}$. (Grau de Recomendação I, Nível de Evidência D). É importante ressaltar que nesta faixa etária, existe a oportunidade única de criar hábitos saudáveis de vida para que, no futuro, não seja necessário modificá-los. É consenso que estas medidas têm chance de sucesso se implementadas num esforço conjunto da família, escola, a comunidade, a sociedade e seu governo, adequando-se, naturalmente às diversidades de cada população.

\section{Tratamento farmacológico da hipertensão arterial}

Deve-se considerar o uso de medicamentos quando as medidas não farmacológicas não promoveram o controle da PA e/ou quando houver evidências de acometimento de órgãos-alvo como hipertrofia ventricular esquerda, microalbuminúria ou alterações vasculares na retina. Estas condições geralmente estão presentes na hipertensão sintomática, na formas secundárias de hipertensão ou em indivíduos que agregam múltiplos fatores de risco cardiovascular ${ }^{(60)}$ (Grau de Recomendação Ila, Nível de Evidência C).

Estudos clínicos expandiram o número de fármacos utilizados para o tratamento da HAS nessa faixa de idade. Entretanto, não há estudos de comparação entre as diversas classes de fármacos bem como o seu impacto nos desfechos clínicos. Desta forma, a escolha da medicação é feita conforme a preferência do especialista e o tratamento visa reduzir a pressão arterial para valores abaixo do percentil 95 para sexo, idade e altura nos casos de hipertensão não complicada ou abaixo do percentil 90, em presença de lesões em órgãos-alvo, DM 2 ou doença renal ${ }^{60,83}$ (Grau de Recomendação lla, Nível de Evidência D). Recomenda-se iniciar o tratamento com um único medicamento, sendo de escolha os inibidores da enzima de conversão da angiotensina (IECA), bloqueadores dos receptores da angiotensina (BRA), antagonistas dos canais de cálcio, betabloqueadores e diuréticos. Classes específicas são usadas preferencialmente em presença de condições especiais como IECA ou BRA em crianças com Diabetes e/ou microalbuminúria e betabloqueadores ou dos antagonistas dos canais de cálcio em portadores de HAS e enxaqueca ${ }^{60,83}$ (Grau de Recomendação I, Nível de Evidência B). Pode-se utilizar associação de drogas, com mecanismos de ação complementares, porém a experiência nessa faixa etária é pequena e não deve ser estimulada (Grau de Recomendação Ilb, Nível de Evidência B). Na Tabela XII há a descrição das drogas aprovadas para o uso na infância e na Figura 3, o algoritmo de tratamento da HAS. 


\section{Tabela XII - Drogas utilizadas no tratamento de hipertensão arterial sistêmica na infância}

\begin{tabular}{|c|c|c|c|c|c|}
\hline Classe & Droga & Dose & Intervalo & GR/NE & Comentários \\
\hline \multirow[t]{6}{*}{ Inibidores da ECA } & Benazepril & $\begin{array}{l}\text { Inicial: } 0,2 \mathrm{mg} / \mathrm{kg} / \mathrm{d} \text { a } 10 \mathrm{mg} / \mathrm{d} \\
\text { Máxima: } 0,6 \mathrm{mg} / \mathrm{kg} / \mathrm{d} \text { a } 40 \mathrm{mg} / \mathrm{d}\end{array}$ & $1 \times d$ & $\mathrm{~B} 1 / 2$ & $\begin{array}{l}\text { Todos os IECA são contra-indicados na } \\
\text { gravidez ou em mulheres com potencial para } \\
\text { engravidar; }\end{array}$ \\
\hline & Captopril & $\begin{array}{l}\text { Inicial: } 0,3-0,5 \mathrm{mg} / \mathrm{kg} / \mathrm{dose} \\
\text { Máxima: } 6 \mathrm{mg} / \mathrm{kg} / \mathrm{d}\end{array}$ & $3 \times d$ & $\mathrm{~B} 1 / 2$ & Monitorar potássio e creatinina \\
\hline & Enalapril & $\begin{array}{l}\text { Inicial: } 0,08 \mathrm{mg} / \mathrm{kg} / \mathrm{d} \text { a } 5 \mathrm{mg} / \mathrm{d} \\
\text { Máxima: } 0,6 \mathrm{mg} / \mathrm{kg} / \mathrm{d} \text { a } 40 \mathrm{mg} / \mathrm{d}\end{array}$ & 1 a $2 \times d$ & $\mathrm{~B} 1 / 2$ & $\begin{array}{l}\text { Tosse e angioedema são mais comuns com } \\
\text { o captopril }\end{array}$ \\
\hline & Fosinopril & $\begin{array}{l}\text { Crianças com mais de } 50 \mathrm{~kg} \\
\text { Inicial: } 5-10 \mathrm{mg} / \mathrm{d} \text { Máxima: } 40 \mathrm{mg} / \mathrm{d}\end{array}$ & $1 \times d$ & $\mathrm{~B} 1 / 2$ & $\begin{array}{l}\text { Benazepril, enalapril, lisinopril e captopril } \\
\text { podem ser preparados em suspensão }\end{array}$ \\
\hline & Lisinopril & $\begin{array}{l}\text { Inicial: } 0,07 \mathrm{mg} / \mathrm{kg} / \mathrm{d} \text { a } 5 \mathrm{mg} / \mathrm{d} \\
\text { Máxima: } 0,6 \mathrm{mg} / \mathrm{kg} / \mathrm{d} \text { a } 40 \mathrm{mg} / \mathrm{d}\end{array}$ & $1 \times d$ & $\mathrm{~B} 1 / 2$ & $\begin{array}{l}\text { FDA aprovou para uso acima de } 6 \text { anos e } \\
\text { clearance de creatinina } \geq 30 \mathrm{ml} / \mathrm{min}\end{array}$ \\
\hline & Quinapril & $\begin{array}{l}\text { Inicial: } 5-10 \mathrm{mg} / \mathrm{d} \\
\text { Máxima: } 80 \mathrm{mg} / \mathrm{d}\end{array}$ & $1 \times d$ & $\mathrm{~B} 1 / 2$ & \\
\hline \multirow[t]{2}{*}{ Bloqueador AT2 } & Irbersartan & $\begin{array}{l}6 \text { a } 12 \text { a: } 75-150 \mathrm{mg} / \mathrm{d} \\
\geq 13 \text { a: } 150-300 \mathrm{mg} / \mathrm{d}\end{array}$ & $1 \times d$ & $\mathrm{~B} 1 / 3$ & As mesmas recomendações dos IECA \\
\hline & Losartan & $\begin{array}{l}\text { Inicial: } 0,7 \mathrm{mg} / \mathrm{kg} / \mathrm{d} \text { a } 50 \mathrm{mg} / \mathrm{d} \\
\text { Máxima: } 1,4 \mathrm{mg} / \mathrm{kg} / \mathrm{d} \text { a } 100 \mathrm{mg} / \mathrm{d}\end{array}$ & $1 \times d$ & $\mathrm{~B} 1 / 2$ & \\
\hline $\begin{array}{l}\text { Alfa e beta } \\
\text { bloqueador }\end{array}$ & Labetalol & $\begin{array}{c}\text { Inicial: } 1-3 \mathrm{mg} / \mathrm{kg} / \mathrm{d} \\
\text { Máxima: } 10-12 \mathrm{mg} / \mathrm{d} \text { a } 1200 \mathrm{mg} / \mathrm{d}\end{array}$ & $2 \times d$ & $\mathrm{~B} 1 / 3$ & $\begin{array}{l}\text { Contraindicação na IC, asma e DM insulino } \\
\text { dependente; a FC é dose limitante; pode } \\
\text { piorar a performance atlética }\end{array}$ \\
\hline \multirow[t]{4}{*}{ Beta bloqueador } & Atenolol & $\begin{array}{c}\text { Inicial: } 0,5-1 \mathrm{mg} / \mathrm{kg} / \mathrm{d} \\
\text { Máxima: } 2 \mathrm{mg} / \mathrm{kg} / \mathrm{d} \text { a } 100 \mathrm{mg} / \mathrm{d}\end{array}$ & 1 a $2 \times d$ & $\mathrm{~B} 1 / 3$ & $\begin{array}{l}\text { Não cardioseletivos (propranolol) são contra } \\
\text { indicados na asma e IC }\end{array}$ \\
\hline & Bisoprolol + HCTZ & $\begin{array}{l}\text { Inicial: } 2,5 / 6,25 \mathrm{mg} / \mathrm{d} \\
\text { Máxima: } 10 / 6,25 \mathrm{mg} / \mathrm{d}\end{array}$ & $1 \times d$ & $\mathrm{~B} 2 / 2$ & $\begin{array}{l}\text { A FC é dose limitante; pode piorar a } \\
\text { performance atlética }\end{array}$ \\
\hline & Metoprolol & $\begin{array}{c}\text { Inicial: } 1-2 \mathrm{mg} / \mathrm{kg} / \mathrm{d} \\
\text { Máxima: } 6 \mathrm{mg} / \mathrm{kg} / \mathrm{d} \text { a } 200 \mathrm{mg} / \mathrm{d}\end{array}$ & $2 \times d$ & $\mathrm{~B} 1 / 3$ & $\begin{array}{l}\text { Não deve ser usado no diabetes insulino- } \\
\text { dependente }\end{array}$ \\
\hline & Propranolol & $\begin{array}{c}\text { Inicial: } 1-2 \mathrm{mg} / \mathrm{kg} / \mathrm{d} \\
\text { Máximo: } 4 \mathrm{mg} / \mathrm{kg} / \mathrm{d} \text { a } 640 \mathrm{mg} / \mathrm{d}\end{array}$ & 2 a $3 \times d$ & $\mathrm{~B} 1 / 2$ & $\begin{array}{l}\text { Uma formulação de liberação prolongada de } \\
\text { propranolol }\end{array}$ \\
\hline \multirow[t]{3}{*}{$\begin{array}{l}\text { Antagonistas dos } \\
\text { canais de cálcio }\end{array}$} & Amlodipina & Crianças $6-17$ a: $2,5-5 \mathrm{mg} / \mathrm{d}$ & $1 \times d$ & $\mathrm{~B} 1 / 2$ & $\begin{array}{l}\text { Anlodipino e Isradipino podem ser } \\
\text { formuladas como suspensão }\end{array}$ \\
\hline & Felodipina & $\begin{array}{l}\text { Inicial: } 2-5 \mathrm{mg} / \mathrm{d} \\
\text { Máxima: } 10 \mathrm{mg} / \mathrm{d}\end{array}$ & $1 \times d$ & $B 1 / 2$ & O comprimido deve ser ingerido inteiro \\
\hline & Nifedipina GITS & $\begin{array}{c}\text { Inicial: 0,25-0,5 mg/kg/d } \\
\text { Máxima: } 3 \mathrm{mg} / \mathrm{kg} / \mathrm{d} \text { a } 120 \mathrm{mg} / \mathrm{d}\end{array}$ & 1 a $2 \times d$ & $\mathrm{~B} 1 / 3$ & \\
\hline $\begin{array}{l}\text { Agonista } \\
\text { central }\end{array}$ & Clonidina & $\begin{array}{l}\text { Crianças } \geq 12 \mathrm{a} \\
\text { Inicial: } 0,2 \mathrm{mg} / \mathrm{d} \\
\text { Máxima: } 2-4 \mathrm{mg} / \mathrm{d}\end{array}$ & $2 \times d$ & $\mathrm{~B} 2 / 4$ & $\begin{array}{l}\text { Tosse, sedação e hipertensão rebote } \\
\text { Preparação transdérmica }\end{array}$ \\
\hline \multirow[t]{5}{*}{ Diurético } & HCTZ & $\begin{array}{c}\text { Inicial: } 1 \mathrm{mg} / \mathrm{kg} / \mathrm{d} \\
\text { Máxima: } 3 \mathrm{mg} / \mathrm{kg} / \mathrm{d} \text { a } 50 \mathrm{mg} / \mathrm{d}\end{array}$ & $1 \times d$ & $B 1 / 3$ & Monitorar eletrólitos \\
\hline & Clortalidona & $\begin{array}{c}\text { Inicial: 0,3 mg/kg/d } \\
\text { Máxima: } 2 \mathrm{mg} / \mathrm{kg} / \mathrm{d} \text { a } 50 \mathrm{mg} / \mathrm{d}\end{array}$ & $1 \times d$ & $\mathrm{~B} 1 / 3$ & Útil em associação com outras drogas \\
\hline & Furosemida & $\begin{array}{l}\text { Inicial: 0,5-2,0 mg/kg/dose } \\
\text { Máxima: } 6 \mathrm{mg} / \mathrm{kg} / \mathrm{d}\end{array}$ & 1 a $2 \times d$ & $\mathrm{~B} 1 / 3$ & Útil na hipert resistente e na I renal \\
\hline & Espironolactona & $\begin{array}{c}\text { Inicial: } 1 \mathrm{mg} / \mathrm{kg} / \mathrm{d} \\
\text { Máxima: } 3,3 \mathrm{mg} / \mathrm{kg} / \mathrm{d} \text { a } 100 \mathrm{mg} / \mathrm{d}\end{array}$ & 1 a $2 \times d$ & $B 1 / 3$ & Cautela com os poupadores de K + IECA \\
\hline & Amilorida & $\begin{array}{l}\text { Inicial: 0,4-0,625 mg/kg/d } \\
\text { Máxima: } 20 \mathrm{mg} / \mathrm{d}\end{array}$ & $1 \times d$ & $\mathrm{~B} 1 / 3$ & \\
\hline \multirow[t]{2}{*}{$\begin{array}{l}\text { Antagonista } \\
\text { alfa periférico }\end{array}$} & Doxazozin & $\begin{array}{l}\text { Inicial: } 1 \mathrm{mg} / \mathrm{d} \\
\text { Máxima: } 4 \mathrm{mg} / \mathrm{d}\end{array}$ & $1 \times d$ & $B 2 / 4$ & Hipotensão postural e síncope na 1 dose \\
\hline & Prazozin & $\begin{array}{l}\text { Inicial: 0,05-0,1 mg/kg/d } \\
\text { Máxima: } 0,5 \mathrm{mg} / \mathrm{kg} / \mathrm{d}\end{array}$ & $3 \times d$ & $\mathrm{~B} 2 / 4$ & \\
\hline \multirow[t]{2}{*}{ Vasodilatador } & Hidralazina & $\begin{array}{c}\text { Inicial: } 0,75 \mathrm{mg} / \mathrm{kg} / \mathrm{d} \\
\text { Máxima: } 7,5 \mathrm{mg} / \mathrm{kg} / \mathrm{d} \text { a } 200 \mathrm{mg} / \mathrm{d}\end{array}$ & 7/B & $\mathrm{B} 2 / 4$ & $\begin{array}{l}\text { Taquicardia e retenção de líquido } \\
\text { Síndrome lúpus-like }\end{array}$ \\
\hline & Minoxidil & $\begin{array}{l}\text { Crianças }<12 \text { a } \\
\text { Inicial: } 0,2 \mathrm{mg} / \mathrm{kg} / \mathrm{d} \\
\text { Máxima: } 50 \mathrm{mg} / \mathrm{d} \\
\text { Crianças } \geq 12 \text { a } \\
\text { Inicial: } 5 \mathrm{mg} / \mathrm{d} \\
\text { Máxima: } 100 \mathrm{mg} / \mathrm{d}\end{array}$ & & $\mathrm{B} 2 / 3$ & $\begin{array}{l}\text { Reservado para HÁ resistente } \\
\text { Uso prolongado pode causar hipertricose }\end{array}$ \\
\hline
\end{tabular}




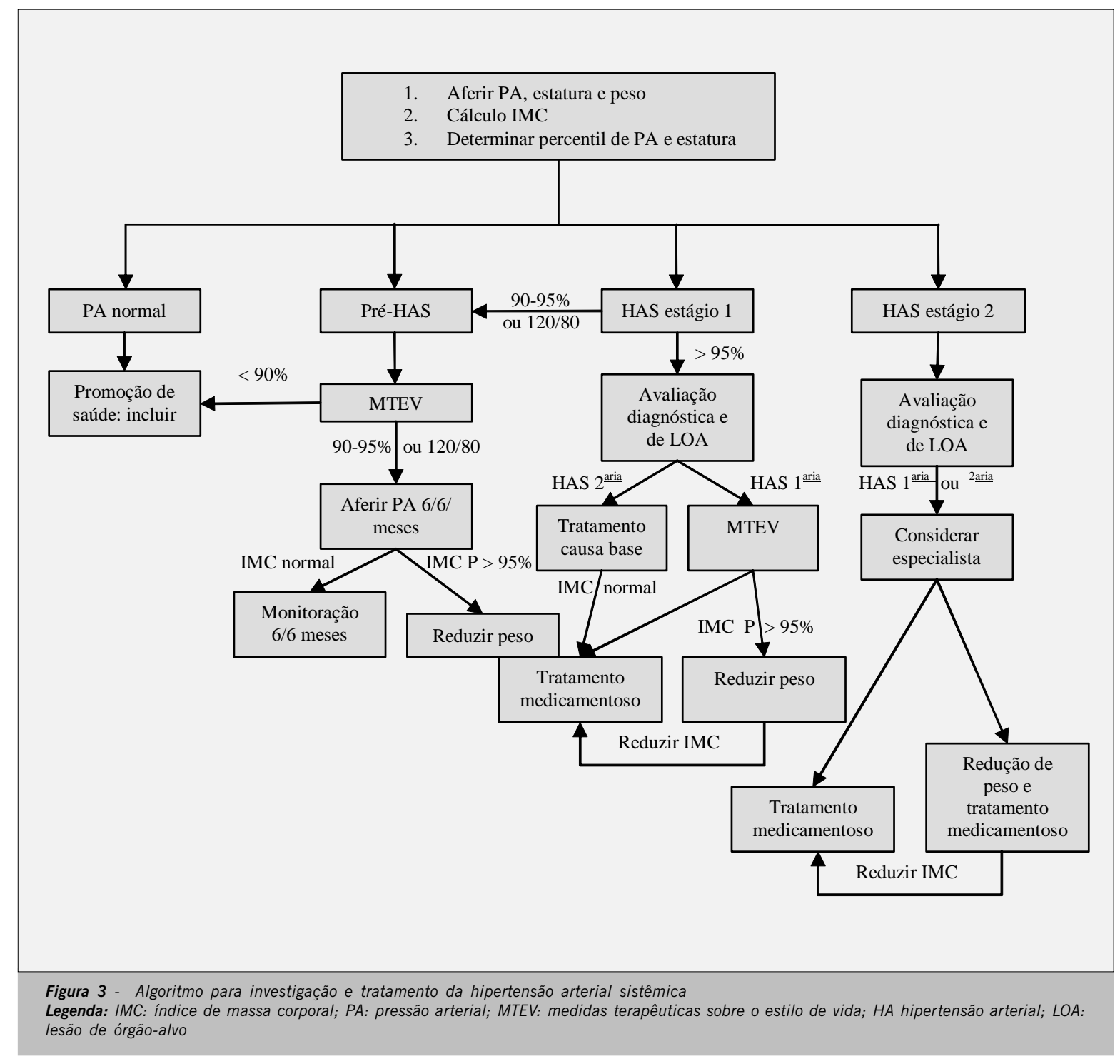

\section{Síndrome metabólica}

\section{Algoritmo de tratamento}

Não existe consenso sobre os critérios de definição da síndrome metabólica para crianças e adolescentes, embora alguns estudos já utilizem o termo também para este grupo populacional. Ao contrário do que ocorre com o diabetes, não existem evidências sobre o benefício do tratamento da síndrome na prevenção de doenças cardiovasculares. Por este motivo o tratamento da síndrome metabólica deve basear-se na mudança do estilo de vida, com ênfase na reeducação alimentar e na prática regular de atividade física. Os objetivos do tratamento são a normalização da glicemia, da PA, dos lipídeos séricos e do peso corporal. A intervenção nutricional visa reduzir a ingestão de calorias, gorduras e açúcares simples e aumentar o consumo de fibras. 0 tratamento farmacológico está reservado aos casos em que há o diagnóstico de diabetes. A Figura 4 resume a conduta nesses pacientes. (Grau de Recomendação lla,
Nível de Evidência D).

\section{Medicamentos utilizados na adolescência}

O único medicamento aprovado pelo FDA para uso na criança e no adolescente no tratamento do diabete melito tipo 2 é a metformina. A metformina mostrou-se efetiva no controle da glicemia e na melhora do perfil lipídico com redução dos níveis de trigicerídeos, VLDL colesterol e LDL colesterol e aumento discreto no HDL. Tem efeito anorético ${ }^{112}$.

\section{Obesidade}

\section{Algoritmo de tratamento de obesidade}

0 tratamento da obesidade é complexo, devido à gama de fatores implicados na sua gênese. No entanto, é consenso de que prática alimentar saudável e combate ao sedentarismo são essenciais. O tratamento visa a normalização do peso, o controle das co-morbidades associadas e a aquisição de hábitos de vida saudáveis ${ }^{113}$. 

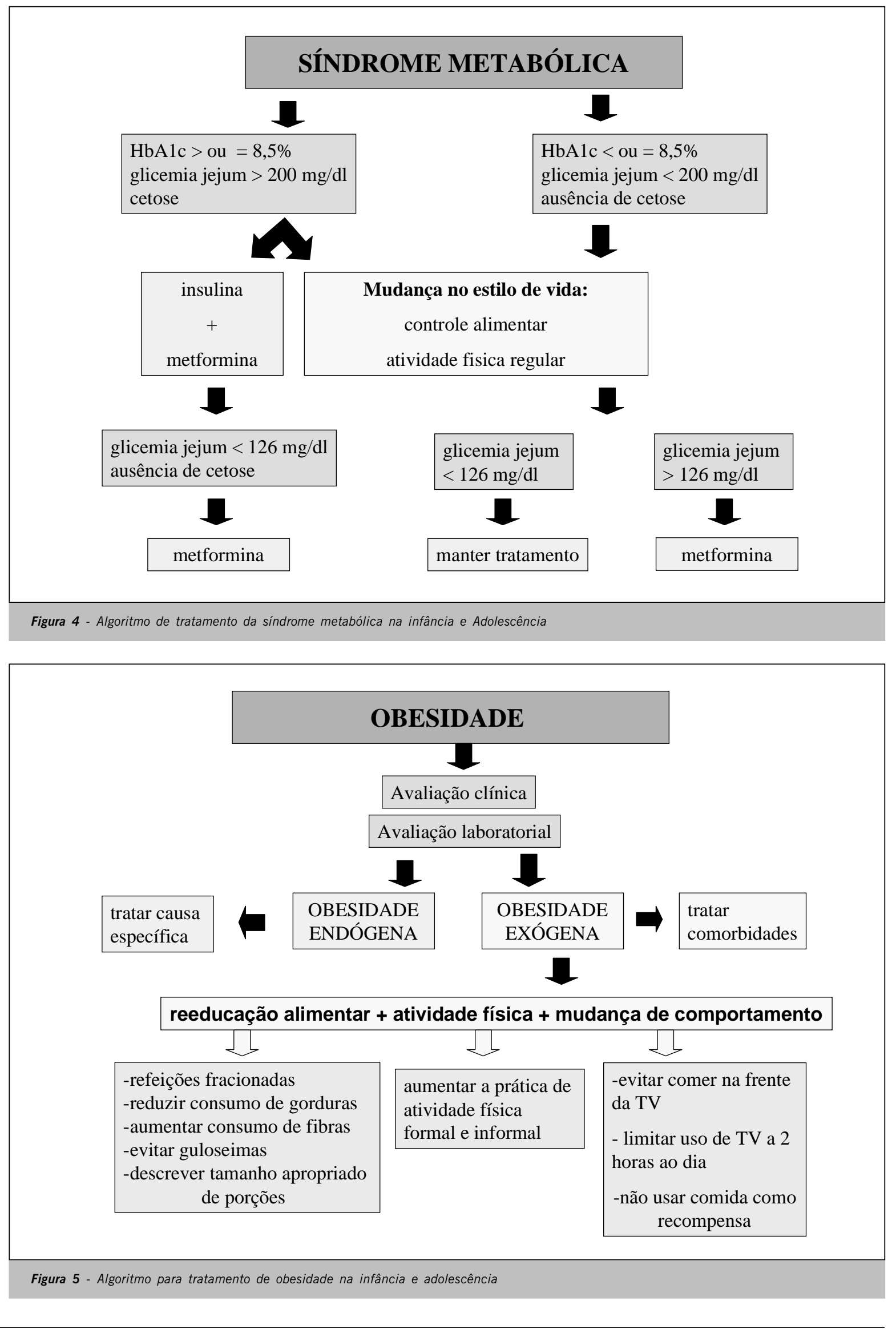


\section{Medicamentos utilizados na infância e adolescência}

O fato de existirem poucos estudos controlados, em longo prazo, demonstrando a segurança e a eficácia do uso de medicamentos para a perda de peso na faixa etária pediátrica tem limitado sua indicação. Dois deles estão aprovados pelo FDA para uso nesta faixa etária: o orlistat (inibidor da lipase pancreática) ${ }^{114}$ e a sibutramina (inibidor da recaptação de aminas) ${ }^{115}$. Estes medicamentos têm se mostrado eficazes na adolescência. Portanto, recomenda-se o tratamento individualizado e focado em causas específicas para tentar limitar o aparecimento de complicações e evitar a progressão da obesidade para a vida adulta116.

\section{REFERÊNCIAS}

1. Gus I, Harzheim E, Zaslavsky C, Medina C Gus M. Prevalence, awareness, and control of systemic arterial hypertension in the state of Rio Grande do Sul. Arq Bras Cardiol 2004; 83(5):429-33.

2. Fuchs SC, Petter JG, Accordi MC, Zen VL, Pizzol AD, Jr., Moreira LB et al. Establishing the prevalence of hypertension. Influence of sampling criteria. Arq Bras Cardiol 2001; 76(6):445-52.

3. IBGE. Pesquisa de Orçamentos Familiares - POF 2002-2003. http://www.ibge.gov.br/home/presidencia/noticias/ noticia impressao.php?id noticia $=278.10-10-2005$.

4. Silva MA, Rivera IR, Ferraz MR, Pinheiro AJ, Alves SW, Moura AA et al. Prevalência de fatores de risco cardiovascular em crianças e adolescentes da rede de ensino da cidade de Maceió. Arq Bras Cardiol 2005; 84(5):387-392.

5. da Silva RC, Malina RM. Prevalência e fatores associado ao sedentarismo em adolescentes de área urbana. Cad Saude Publica 2000; 16(4):1091-1097.

6. Moura EC, de Castro CM, Mellin AS, de Figueiredo DB. Perfil lipídico em escolares de Campinas,SP,Brasil. Rev Saude Publica 2000; 34(5):499-505

7. Giuliano IC, Coutinho MS, Freitas SF, Pires MM, Zunino JN, Ribeiro $R Q$. Lípides séricos em crianças e adolescentes da rede escolar de Florianópolis - Estudo Floripa Saudável 2040. Arq Bras Cardiol 2005; 85(2):85-91

8. Bordin R, Nipper VB, Silva JO, Bortolomiol L. Prevalência de tabagismo entre escolares em municípios de área metropolitana da região Sul, Brasil, 1991. Cad Saude Publica 1993; 9(2):185-189.

9. Levantamento sobre o uso de drogas entre estudantes de $1^{\circ} \mathrm{e} 2^{\circ}$ graus em 10 capitais brasileiras. Centro Brasileiro de Informações sobre Drogas Psicotrópicas (CEBRID), editor. 1997. 1997.

10. IBGE. Tendências Demográficas. Uma análise dos resultados da amostra do censo demográfico 2000. http://www.datasus.br/ . 10-102005. Ministério do Planejamento,Orçamento e Gestão.

11. Batista Filho M, Rissin A. A transição nutricional no Brasil tendências regionais e temporais. Caderno de Saúde Pública 2003; 19(suppl 1):181-91

12. Mendonca CP, dos Anjos LA. Aspectos das práticas alimentares e da atividade física como determinantes do crescimento do sobrepeso/ obesidade no Brasil . Cad Saude Publica 2004; 20(3):698-709.

13. Abrantes MM, Lamounier JA, Colosimo EA. Prevalência de sobrepeso e obesidade em crianças e adolescentes das regiões Sudeste e Nordeste. J Pediatr (Rio J) 2002; 78(4):335-40.

14. Barker DJ, Hanson MA. Altered regional blood flow in the fetus: the origins of cardiovascular disease? Acta Paediatr 2004; 93(12):1559-60.

15. Barker DJ. In utero programming of cardiovascular disease. Theriogenology 2000; 53(2):555-74.

16. Barker DJ. Fetal origins of coronary heart disease. Bmj 1995 ; 311(6998):171-4.

17. Barker DJ, Martyn CN, Osmond C, Wield GA. Abnormal liver growth in utero and death from coronary heart disease. Bmj 1995; 310(6981):703-4.
18. Wintour EM, Johnson K, Koukoulas I, Moritz K, Tersteeg M, Dodic M. Programming the cardiovascular system, kidney and the brain-a review. Placenta 2003; 24 Suppl A:65-71.

19. Hattersley AT, Tooke JE. The fetal insulin hypothesis: an alternative explanation of the association of low birthweight with diabetes and vascular disease. Lancet 1999; 353(9166):1789-92

20. de Onis M, Blossner M, Villar J. Levels and patterns of intrauterine growth retardation in developing countries. Eur J Clin Nutr 1998; 52 Suppl 1:5-15

21. Meshari AA, De Silva S, Rahman I. Fetal macrosomia-maternal risks and fetal outcome. Int J Gynaecol Obstet 1990; 32(3):215-22.

22. Pribylova H, Dvorakova L. Long-term prognosis of infants of diabetic mothers. Relationship between metabolic disorders in newborns and adult offspring. Acta Diabetol 1996; 33(1):30-4

23. Merzouk H, Bouchenak M L Loukidi B, Madani S, Prost J, Belleville J. Fetal macrosomia related to maternal poorly controlled type 1 diabetes strongly impairs serum lipoprotein concentrations and composition. J Clin Pathol 2000; 53(12):917-23.

24. Merzouk H, Madani S, Prost J, Loukidi B, Meghelli-Bouchenak M, Belleville J. Changes in serum lipid and lipoprotein concentrations and compositions at birth and after 1 month of life in macrosomic infants of insulin-dependent diabetic mothers. Eur J Pediatr 1999 , 158(9):750-6.

25. Curhan GC, Chertow GM, Willett WC, Spiegelman D, Colditz GA, Manson JE et al. Birth weight and adult hypertension and obesity in women. Circulation 1996; 94(6):1310-5.

26. Fowden AL. The role of insulin in prenatal growth. J Dev Physiol 1989; 12(4):173-82.

27. Barker DJ, Eriksson JG, Forsen T, Osmond C. Fetal origins of adult disease: strength of effects and biological basis. Int J Epidemiol 2002; 31(6):1235-9.

28. Lawlor DA, Davey Smith G, Ebrahim S. Birth weight is inversely associated with coronary heart disease in post-menopausal women: findings from the British women's heart and health study. J Epidemiol Community Health 2004; 58(2): 120-5

29. Palinski W, Napoli C. The fetal origins of atherosclerosis: maternal hypercholesterolemia, and cholesterol-lowering or antioxidant treatment during pregnancy influence in utero programming and postnatal susceptibility to atherogenesis. Faseb J 2002; 16(11):1348-60.

30. Walker SP, Gaskin P, Powell CA, Bennett FI, Forrester TE, GranthamMcGregor S. The effects of birth weight and postnatal linear growth retardation on blood pressure at age 11-12 years. J Epidemiol Community Health 2001; 55(6):394-8.

31. Singhal A, Cole TJ, Lucas A. Early nutrition in preterm infants and later blood pressure: two cohorts after randomised trials. Lancet 2001; 357(9254):413-9.

32. Fall $\mathrm{CH}$, Stein CE, Kumaran $\mathrm{K}, \mathrm{Cox} \mathrm{V}$, Osmond C, Barker DJ et al. Size at birth, maternal weight, and type 2 diabetes in South India. Diabet Med 1998; 15(3):220-7. 
33. Gillman MW, Rifas-Shiman SL, Camargo CA, Jr., Berkey CS, Frazier $\mathrm{AL}$, Rockett HR et al. Risk of overweight among adolescents who were breastfed as infants. Jama 2001; 285(19):2461-7.

34. Li L, Parsons TJ, Power C. Breast feeding and obesity in childhood: cross sectional study. Bmj 2003; 327(7420):904-5.

35. Dietz WH. Breastfeeding may help prevent childhood overweight. Jama 2001;285(19):2506-7.

36. Roberts SB. Prevention of hypertension in adulthood by breastfeeding? Lancet 2001; 357(9254):406-7.

37. Marks D, Thorogood M, Neil HA, Humphries SE. A review on the diagnosis, natural history, and treatment of familial hypercholesterolaemia. Atherosclerosis 2003; 168(1):1-14.

38. Bertolini S, Pisciotta L, Di Scala L, Langheim S, Bellocchio A, Masturzo $P$ et al. Genetic polymorphisms affecting the phenotypic expression of familial hypercholesterolemia. Atherosclerosis 2004; 174(1):57-65.

39. Tracy RE, Newman WP3, Wattigney WA, Berenson GS. Risk factors and atherosclerosis in youth autopsy findings of the Bogalusa Heart Study. Am J Med Sci 1995; 310 Suppl 1:37-41.

40. Bachorik PS, Ross JW. National Cholesterol Education Program recommendations for measurement of low-density lipoprotein cholesterol: executive summary. The National Cholesterol Education Program Working Group on Lipoprotein Measurement. Clin Chem 1995; 41(10):1414-20.

41. Stein EA, Myers GL. National Cholesterol Education Program recommendations for triglyceride measurement: executive summary. The National Cholesterol Education Program Working Group on Lipoprotein Measurement. Clin Chem 1995; 41(10):1421-6.

42. Pichet G, Lopes LM, Cotrim FLS, Scartezini M, Lima JCC, Martinez TLR. Lípides e lipoproteínas: interpretação dos dados laboratoriais e metodologias. In: Martinez TLR, editor. Condutas clínicas nas Dislipidemias. Belo Horizonte: Health, 1997: 85-115.

43. Santos RD. III Diretrizes Brasileiras sobre Dislipidemias e Diretriz de Prevenção da Aterosclerose do Departamento de Aterosclerose da Sociedade Brasileira de Cardiologia. Arq Bras Cardiol 2001; 77 Suppl 3:1-48.

44. Branchi A, Rovellini A, Fiorenza AM, Torri A, Prandi W, Tomella C et al. Estimation of cardiovascular risk: total cholesterol versus lipoprotein profile. Int J Clin Lab Res 1994; 24(2):106-12.

45. Friedewald WT, Levy RI, Fredrickson DS. Estimation of the concentration of low-density lipoprotein cholesterol in plasma, without use of the preparative ultracentrifuge. Clin Chem 1972; 18(6):499-502.

46. Rifai N, Merrill JR, Holly RG. Postprandial effect of a high fat meal on plasma lipid, lipoprotein cholesterol and apolipoprotein measurements. Ann Clin Biochem 1990; 27 ( Pt 5):489-93.

47. Executive Summary of The Third Report of The National Cholestero Education Program (NCEP) Expert Panel on Detection, Evaluation, And Treatment of High Blood Cholesterol In Adults (Adult Treatment Panel III). Jama 2001;285(19):2486-97.

48. Lichtenstein AH, Deckelbaum RJ. AHA Science Advisory. Stanol/sterol ester-containing foods and blood cholesterol levels. A statement for healthcare professionals from the Nutrition Committee of the Council on Nutrition, Physical Activity, and Metabolism of the American Heart Association. Circulation 2001; 103(8):1177-9.

49. Brotons C, Ribera A, Perich RM, Abrodos D, Magana P, Pablo S et al. Worldwide distribution of blood lipids and lipoproteins in childhood and adolescence: a review study. Atherosclerosis 1998; 139(1):1-9.

50. Ribeiro RQ. Epidemiologia das dislipidemias em escolares. Universidade Federal de MInas Gerais, 2000.

51. Morrison JA, Sprecher DL, Biro FM, Apperson-Hansen C, Dipaola LM. Serum testosterone associates with lower high-density lipoprotein cholesterol in black and white males, 10 to 15 years of age, through lowered apolipoprotein AI and All concentrations. Metabolism 2002; 51(4):432-437.

52. Goran MI, Gower BA. Longitudinal study on pubertal insulin resistance. Diabetes 2001; 50(11):2444-2450.

53. Hoffman RP, Vicini P, Sivitz WI, Cobelli C. Pubertal adolescent malefemale differences in insulin sensitivity and glucose effectiveness determined by the one compartment minimal model. Pediatr Res 2000 48(3):384-388.

54. Travers SH, Jeffers BW, Bloch CA, Hill JO, Eckel RH. Gender and Tanner stage differences in body composition and insulin sensitivity in early pubertal children. J Clin Endocrinol Metab 1995; 80(1):172-178.

55. Yamagishi SI, Edelstein D, Du XL, Brownlee M. Hyperglycemia potentiates collagen-induced platelet activation through mitochondrial superoxide overproduction. Diabetes 2001; 50(6):1491-1494.

56. Meier $\mathrm{M}$, King GL. Protein kinase $\mathrm{C}$ activation and its pharmacologica inhibition in vascular disease. Vasc Med 2000; 5(3):173-185.

57. McFarlane SI, Banerji M, Sowers JR. Insulin resistance and cardiovascular disease. J Clin Endocrinol Metab 2001; 86(2):713-718.

58. Keskin M, Kurtoglu S, Kendirci M, Atabek ME, Yazici C. Homeostasis model assessment is more reliable than the fasting glucose/insulin ratio and quantitative insulin sensitivity check index for assessing insulin resistance among obese children and adolescents. Pediatrics 2005 115(4):e500-e503.

59. Brandao AP, Brandao AA, Araujo EM. The significance of physical development on the blood pressure curve of children between 6 and 9 years of age and its relationship with familial aggregation. J Hypertens Suppl 1989; 7(1):S37-S39.

60. The fourth report on the diagnosis, evaluation, and treatment of high blood pressure in children and adolescents. Pediatrics 2004; 114(2 Suppl 4th Report):555-576.

61. Lurbe E, Sorof JM, Daniels SR. Clinical and research aspects of ambulatory blood pressure monitoring in children. J Pediatr 2004 144(1):7-16.

62. Guimaraes JI, Gomes MA, Mion D, Jr., Nobre F, Mendonca MA, Cruz LL et al. III Diretrizes Brasileiras para MAPA/MRPA. Arq Bras Cardiol 2003; 80(2):225-233.

63. Sorof JM, Alexandrov AV, Cardwell G, Portman RJ. Carotid artery intimal-medial thickness and left ventricular hypertrophy in children with elevated blood pressure. Pediatrics 2003; 111(1):61-66.

64. de Simone G, Daniels SR, Devereux RB, Meyer RA, Roman MJ, de Divitiis $O$ et al. Left ventricular mass and body size in normotensive children and adults: assessment of allometric relations and impact of overweight. J Am Coll Cardiol 1992; 20(5):1251-1260.

65. Daniels SR, Meyer RA, Liang YC, Bove KE. Echocardiographically determined left ventricular mass index in normal children, adolescents and young adults. J Am Coll Cardiol 1988; 12(3):703-708.

66. Arnett DK, Glasser SP, McVeigh G, Prineas R, Finklestein S, Donahue $\mathrm{R}$ et al. Blood pressure and arterial compliance in young adults: the Minnesota Children's Blood Pressure Study. Am J Hypertens 2001; 14(3):200-205

67. Sinaiko AR, Gomez-Marin O, Prineas RJ. Effect of low sodium diet or potassium supplementation on adolescent blood pressure. Hypertension 1993; 21(6 Pt 2):989-994.

68. Berenson GS, Srinivasan SR, Hunter SM, Nicklas TA, Freedman DS Shear $C L$ et al. Risk factors in early life as predictors of adult heart disease: the Bogalusa Heart Study. Am J Med Sci 1989; 298(3):141-51.

69. Campbell PT, Katzmarzyk PT, Malina RM, Rao DC, Perusse L, Bouchard C. Stability of adiposity phenotypes from childhood and 
adolescence into young adulthood with contribution of parental measures. Obes Res 2001; 9(7):394-400.

70. Freedman DS, Khan LK, Dietz WH, Srinivasan SR, Berenson GS. Relationship of childhood obesity to coronary heart disease risk factors in adulthood: the Bogalusa Heart Study. Pediatrics 2001; 108(3):712-718.

71. Weiss R, Dziura J, Burgert TS, Tamborlane WV, Taksali SE, Yeckel CW et al. Obesity and the metabolic syndrome in children and adolescents. N Engl J Med 2004; 350(23):2362-2374.

72. Lima SC, Arrais RF, Almeida MG, Souza ZM, Pedrosa LF. Perfil lipídico e peroxidação de lipídeos no plasma em crianças e adolescentes com sobrepeso e obesidade. J Pediatr (Rio J) 2004; 80(1):23-28.

73. Glowinska B, Urban M, Koput A, Galar M. New atherosclerosis risk factors in obese, hypertensive and diabetic children and adolescents. Atherosclerosis 2003; 167(2):275-286

74. Freedman DS. Clustering of coronary heart disease risk factors among obese children. J Pediatr Endocrinol Metab 2002 ; 15(8):1099-1108.

75. Haszon I, Papp F, Kovacs J, Bors M, Nemeth I, Bereczki C et al. Platelet aggregation, blood viscosity and serum lipids in hypertensive and obese children. Eur J Pediatr 2003; 162(6):385-390.

76. Robinson RF, Batisky DL, Hayes JR, Nahata MC, Mahan JD. Body mass index in primary and secondary pediatric hypertension. Pediatr Nephrol 2004; 19(12):1379-1384.

77. Hanevold C, Waller J, Daniels S, Portman R, Sorof J. The effects of obesity, gender, and ethnic group on left ventricular hypertrophy and geometry in hypertensive children: a collaborative study of the International Pediatric Hypertension Association. Pediatrics 2004; 113(2):328-333.

78. Uiterwaal CS, Witteman JC, de Bruijn AM, Hofman A, Grobbee DE. Families and natural history of lipids in childhood: an 18-year followup study. Am J Epidemiol 1997; 145(9):777-785.

79. Clinical Growth Charts. http://www.cdc.gov/nchs/about/major/ nhanes/growthcharts/clinical_charts.htm . 2004. CDC-NCHS. 1011-2005.

80. Williams CL, Hayman LL, Daniels SR, Robinson TN, Steinberger J, Paridon $S$ et al. Cardiovascular health in childhood: A statement for health professionals from the Committee on Atherosclerosis, Hypertension, and Obesity in the Young (AHOY) of the Council on Cardiovascular Disease in the Young, American Heart Association. Circulation 2002; 106(1):143-60.

81. Thompson FE, Byers T. Dietary assessment resource manual. J Nutr 1994; 124(11 Suppl):2245S-2317S.

82. Goran MI, Kaskoun M, Johnson R. Determinants of resting energy expenditure in young children. J Pediatr 1994; 125(3):362-367.

83. Kavey RE, Daniels SR, Lauer RM, Atkins DL, Hayman LL, Taubert K. American Heart Association guidelines for primary prevention of atherosclerotic cardiovascular disease beginning in childhood. Circulation 2003; 107(11):1562-1566.

84. Fletcher GF, Balady G, Blair SN, Blumenthal J, Caspersen C, Chaitman $B$ et al. Statement on exercise: benefits and recommendations for physical activity programs for all Americans. A statement for health professionals by the Committee on Exercise and Cardiac Rehabilitation of the Council on Clinical Cardiology, American Heart Association. Circulation 1996; 94(4):857-862.

85. Physical fitness and activity in schools. American Academy of Pediatrics. Pediatrics 2000; 105(5):1156-1157.

86. Maron BJ, Chaitman BR, Ackerman MJ, Bayes dL, Corrado D, Crosson JE et al. Recommendations for physical activity and recreational sports participation for young patients with genetic cardiovascular diseases. Circulation 2004; 109(22):2807-2816.

87. Berenson GS, Srinivasan SR, Bao W, Newman WP, III, Tracy RE, Wattigney WA. Association between multiple cardiovascular risk factors and atherosclerosis in children and young adults. The Bogalusa Heart Study. N Engl J Med 1998; 338(23):1650-1656.

88. Ball EJ, O'Connor J, Abbott R, Steinbeck KS, Davies PS, Wishart C et al. Total energy expenditure, body fatness, and physical activity in children aged 6-9y. Am J Clin Nutr 2001; 74(4):524-528.

89. IBGE. Dados populacionais. http://www.ibge.gov.br . 8-10-2005. 1010-2005.

90. INCA. Tabagismo. www.inca.gov.br/tabagismo . 2005. 10-10-2005.

91. Batra V, Patkar AA, Berrettini WH, Weinstein SP, Leone FT. The genetic determinants of smoking. Chest 2003; 123(5):1730-1739.

92. Comorbidade psiquiátrica em tabagismo. 00; III Simpósio internacional sobre o tratamento do tabagismo, 2005.

93. Jin C, Rossignol AM. Effects of passive smoking on respiratory illness from birth to age eighteen months, in Shanghai, People's Republic of China. J Pediatr 1993; 123(4):553-558.

94. Hanson K, Allen S, Jensen S, Hatsukami D. Treatment of adolescent smokers with the nicotine patch. Nicotine Tob Res 2003; 5(4): 515-526.

95. Romaldini CC, Issler H, Cardoso AL, Diament J, Forti N. Fatores de risco para aterosclerose em crianças e adolescentes com história familiar de doença arterial coronariana prematura. J Pediatr (Rio J) 2004; 80(2):135-140.

96. Beck A, Freeman A. Cognitive therapy of personality disorders. New York: Gulford Press, 1990.

97. Lipp MEN. Como enfrentar o estresse infantil. São Paulo: Cortez, 1991.

98. Steptoe A, Marmot M. Burden of psychosocial adversity and vulnerability in middle age: associations with biobehavioral risk factors and quality of life. Psychosom Med 2003; 65(6):1029-1037.

99. Jennings JR, Kamarck TW, Everson-Rose SA, Kaplan GA, Manuck SB, Salonen JT. Exaggerated blood pressure responses during mental stress are prospectively related to enhanced carotid atherosclerosis in middleaged Finnish men. Circulation 2004; 110(15):2198-2203.

100.Calais SL, Andrade LB. Diferenças de sexo e escolaridade na manifestação de stress em adultos jovens. Psicologia Reflexão e Crítica, Rio Grande do Sul 2003; 16(2):257-263.

101.Lipp MEN. Crianças estressadas: sintomas, causas e soluções. Campinas: Papirus, 2003.

102. Tonstad S. A rational approach to treating hypercholesterolaemia in children. Weighing the risks and benefits. Drug Saf 1997; 16(5):330-341.

103. Tonstad S. Role of lipid-lowering pharmacotherapy in children. Paediatr Drugs 2000; 2(1):11-22.

104. Tonstad S, Sivertsen M, Aksnes L, Ose L. Low dose colestipol in adolescents with familial hypercholesterolaemia. Arch Dis Child 1996; 74(2):157-160.

105.Xydakis AM, Guyton JR, Chiou P, Stein JL, Jones PH, Ballantyne CM. Effectiveness and tolerability of ezetimibe add-on therapy to a bile acid resin-based regimen for hypercholesterolemia. Am J Cardiol 2004; 94(6):795-797.

106. Gagne C, Gaudet D, Bruckert E. Efficacy and safety of ezetimibe coadministered with atorvastatin or simvastatin in patients with homozygous familial hypercholesterolemia. Circulation 2002; 105(21):2469-2475.

107. Salen G, von Bergmann K, Lutjohann D, Kwiterovich P, Kane J, Patel $\mathrm{SB}$ et al. Ezetimibe effectively reduces plasma plant sterols in patients with sitosterolemia. Circulation 2004; 109(8):966-71.

108.Sacks FM, Svetkey LP, Vollmer WM, Appel LJ, Bray GA, Harsha D et al. Effects on blood pressure of reduced dietary sodium and the Dietary Approaches to Stop Hypertension (DASH) diet. DASH-Sodium Collaborative Research Group. N Engl J Med 2001; 344(1):3-10. 
109.Bao W, Threefoot SA, Srinivasan SR, Berenson GS. Essential hypertension predicted by tracking of elevated blood pressure from childhood to adulthood: the Bogalusa Heart Study. Am J Hypertens 1995; 8(7):657-665.

110. He J, Whelton PK, Appel LJ, Charleston J, Klag MJ. Long-term effects of weight loss and dietary sodium reduction on incidence of hypertension. Hypertension 2000; 35(2):544-549.

111. Kelley GA, Kelley KS, Tran ZV. The effects of exercise on resting blood pressure in children and adolescents: a meta-analysis of randomized controlled trials. Prev Cardiol 2003; 6(1):8-16.

112. Benavides S, Striet J, Germak J, Nahata MC. Efficacy and safety of hypoglycemic drugs in children with type 2 diabetes mellitus. Pharmacotherapy 2005; 25(6):803-809.
113.Dao HH, Frelut ML, Oberlin F, Peres G, Bourgeois P, Navarro J. Effects of a multidisciplinary weight loss intervention on body composition in obese adolescents. Int J Obes Relat Metab Disord 2004; 28(2):290-299

114.Chanoine JP, Hampl S, Jensen C, Boldrin M, Hauptman J. Effect of orlistat on weight and body composition in obese adolescents: a randomized controlled trial. Jama 2005; 293(23):2873-2883.

115.Godoy-Matos A, Carraro L, Vieira A, Oliveira J, Guedes EP, Mattos L et al. Treatment of obese adolescents with sibutramine: a randomized, double-blind, controlled study. J Clin Endocrinol Metab 2005 90(3):1460-1465.

116. Joffe A. Pharmacotherapy for adolescent obesity: a weighty issue. Jama 2005; 293(23):2932-2934.

\section{Potencials Conflitos de Interesse}

\section{Adriana Forti}

- Conferencista/palestrante em eventos patrocinados pela indústria: Pfizer, Aventis, Astra Zeneca e Novo. Membro do ILIB.

\section{Bruce Duncan}

- Patrocínio de transporte: Astra-Zeneca

- Patrocínio em estudos clínicos: Bristol Myers Squibb Foundation

- Conferencista/palestrante em eventos patrocinados pela indústria: Medley

\section{Bruno Caramelli}

- Patrocínio de transporte e/ou hospedagem em congressos: Abbott, Pfizer, Schering-Plough, AstraZeneca, Roche.

- Patrocínio em estudos clínicos e/ou experimentais subvencionados pela indústria: Pfizer, Roche, AstraZeneca.

- Conferencista/palestrante em evento patrocinados pelos Laboratórios Farmacêuticos: Abbott, Pfizer, ScheringPlough, AstraZeneca, Roche.

- Comitês normativos dos seguintes Laboratórios Farmacêuticos: Schering-Plough, AstraZeneca, Novartis.

\section{Fernanda Luisa Ceragioli Oliveira}

- Patrocínio de transporte e/ou hospedagem em Congressos:Nestlé e Support.

- Ser conferencista/palestrante em eventos patrocinados pela indústria: Nestlé e Support .

- Participar de comitês normativos de estudos científicos patrocinados pela indústria: Nestlé.

- Receber apoio institucional da indústria: Nestlé, Support

\section{Francisco Fonseca}

- Conferencista/palestrante em eventos patrocinados pelaindústria: Pfizer, Astra Zeneca, Libbs, Novartis, Merck Sharp Dohme, Abbott, Unilever, Membro do Ilib.

\section{Isabela Giuliano}

- Patrocínio de transporte e/ou hospedagem em congressos: Abbott, Bristol Myers Squibb

- Conferencista/palestrante em evento patrocinados pelos Laboratórios Farmacêuticos: Abott

\section{Lilton C Martinez}

- Conferencista/palestrante em evento patrocinados pelos Laboratórios Farmacêuticos: Merck Sharp Dohme

\section{Mauro Fisberg}

- Patrocínio de transporte e/ou hospedagem em congressos: Abbott, Danone, Merck Sharp e Altana

- Assessoria científica: Danone, Altana, Merck Sharp, Nestle

- Patrocínio em estudos clínicos e/ou experimentais subvencionados pela Indústria: Merck Sharp, Nestle, Danone, Unilever

- Conferencista/palestrante em evento patrocinados pelos Laboratórios Farmacêuticos: Abbott

\section{Raul D. Santos}

- Conferencista/palestrante em evento patrocinados pelos Laboratórios Farmacêuticos: Pfizer, Merck Sharpe Dohme, Abbott e Schering Plough. Membro do ILIB

\section{Sidney Fernandes}

- Patrocínio de transporte e/ou hospedagem em congressos: Astra Zeneca

Os demais co-autores não declararam qualquer potencial conflito de interesses. 